Bruna Nascimento da Silva ${ }^{1}$ Lúcia Dias da Silva Guerra² Leonardo Carnut ${ }^{3}$

\title{
EFETIVIDADE DO DIREITO À ALIMENTAÇÃO: O QUE A PRODUÇÃO CIENTÍFICA NAS ÁREAS DO DIREITO E DA SAÚDE COLETIVA POSSIBILITAM COMPREENDER?
}

Effectiveness of the right to food: what does scientific production in the areas of law and public health make it possible to understand?

${ }^{1}$ Faculdades Oswaldo Cruz. Centro de Pós-Graduação e Pesquisa Oswaldo Cruz. São Paulo/SP, Brasil.

${ }^{2}$ Universidade de São Paulo. Faculdade de Saúde Pública. São Paulo/SP. Brasil.

${ }^{3}$ Universidade Federal de São Paulo. São Paulo/SP. Brasil.

Correspondência: Bruna Nascimento da Silva. E-mail: b.nasc.s@gmail.com

Recebido: 23/08/2019. Revisão: 17/01/2020. Aprovado: 14/02/2020. 


\section{RESUMO}

A alimentação é um direito humano fundamental, de cunho social e político, cabendo ao Estado garantir sua efetividade e executar medidas de combate à omissão a quaisquer violações. O objetivo do presente estudo foi compreender como a efetividade do direito à alimentação é abordada pela literatura científica, tanto na área do direito quanto na da saúde coletiva. Tratou-se de um estudo com abordagem qualitativa, realizado por meio de análise de conteúdo lexical da produção científica nas áreas escolhidas, utilizando-se o software Iramuteq. Concluiu-se que existe uma diferença significativa na abordagem da efetividade do direito à alimentação por pesquisadores do direito e da saúde coletiva. Ainda há muito a se avançar na pesquisa e análise sobre a efetividade desse direito em termos concretos e no alcançar na vida de todos os brasileiros.

\section{Palavras-Chave}

Direito à Alimentação; Efetividade; Fome; Segurança Alimentar e Nutricional.

\section{ABSTRACT}

The right to food is a fundamental human right, of a social and political nature, and it is up to the State to guarantee its effectiveness and implement measures to combat the omission of any violations. The objective of the present study was to understand how the effectiveness of the right to food is addressed in the scientific literature both in the area of law and of public health. This was a study with qualitative approach conducted through a lexical content analysis of scientific production in the chosen areas, using the Iramuteq software. It was concluded that there is a significant difference in the approach regarding the effectiveness of the right to food by researchers of both areas. There is still much to advance in the research and analysis on the effectiveness of this right in concrete terms and in reaching the life of all Brazilians.

\section{Keywords}

Right to Food; Effectiveness; Hunger; Food and Nutrition Security. 


\section{Introdução}

Os direitos sociais são considerados direitos fundamentais à dignidade da pessoa humana e estão positivados na Constituição Federal de $1988(\mathrm{CF} / 88)^{1}$. No entanto, o direito à alimentação foi incluído no artigo $6^{\circ}$ da $\mathrm{CF} / 88$, que estabelece quais são os direitos sociais, somente em 2010, por força da Emenda Constitucional n. $64^{2}$.

Sendo alvo da operacionalidade das políticas públicas, o direito à alimentação passou a ser conhecido como direito humano à alimentação adequada (DHAA). Essa nomenclatura justifica-se pelo fato de não ser apenas um direito social, circunscrito à jurisdição brasileira, mas também um direito político, reconhecido internacionalmente devido a seu caráter eminentemente humano.

De aplicabilidade imediata, o DHAA e sua efetividade podem ser, em alguma medida, identificados pela concretização e realização do direito essencial à vida digna e à saúde. Mesmo sendo dotado de força normativa, o Estado tem apresentado dificuldades de se comprometer e executar medidas para a efetivação desse direito, o combate a suas cotidianas violações ${ }^{3}$ - inclusive, como ocorrido recentemente, muitas vezes não reconhece tais violações ${ }^{4}$.

Nunca é demais lembrar que os direitos sociais, por sua vez, estão relacionados com a luta dos trabalhadores contra a exploração do capital. Trata-se da luta por melhores condições de vida e de trabalho - o que inclui o direito de greve pela regulamentação da jornada de trabalho e por salários dignos, ou seja, por sua sobrevivência em um sistema que os oprime. Assim, embora essa luta tenha como fundamento a dignidade humana em seu aspecto individual, trata-se também da luta coletiva dos trabalhadores contra condições desumanas e degradantes às quais são submetidos 5 .

A alimentação e a nutrição adequadas são requisitos básicos necessários à promoção e proteção da saúde e, além disso, trazem em sua essência a discussão da

\footnotetext{
${ }^{1}$ BRASIL. Constituição da República Federativa do Brasil de 1988. Disponível em: http://www.planalto.gov. br/ccivil_03/constituicao/constituicaocompilado.htm. Acesso em: 23 abr. 2021.

${ }^{2}$ BRASIL. Emenda Constitucional n. 64, de 4 de fevereiro de 2010. Altera o art. $6^{\circ}$ da Constituição Federal, para introduzir a alimentação como direito social. Disponível em: http://www.planalto.gov.br/ccivil_03/ constituicao/emendas/emc/emc64.htm. Acesso em: 23 abr. 2021.

${ }^{3}$ SOARES, Sônia. Análise do direito humano à alimentação adequada: um direito social e político. Revista de Direito Sanitário, São Paulo, v. 19 n. 2, p. 36-54, jul./out. 2018. Disponível em: https://www.revistas.usp.br/ rdisan/article/view/152569/149064. Acesso em 13 ago. 2019. https://dx.doi.org/10.11606/issn.23169044.v19i2p36-54.

${ }^{4}$ COPLE, Júlia. 'Passar fome no Brasil é uma grande mentira', diz Bolsonaro. O Globo, 19 jul. 2019. Disponível em: https://oglobo.globo.com/brasil/passar-fome-no-brasil-uma-grande-mentira-diz-bolsonaro-23818496. Acesso em 18 ago. 2019.

${ }^{5}$ OLIVEIRA SOBRINHO, Afonso Soares. A dignidade humana como afirmação histórica. Revista Espaço Acadêmico, v. 13, n. 144, p. 54-62, maio 2013. Disponível em: https://periodicos.uem.br/ojs/index.php/ EspacoAcademico/article/view/19627/11102.
} 
garantia à vida e à cidadania, conectadas à realidade social das pessoas ${ }^{6,7}$. Nos termos de Valente ${ }^{8}$, o direito humano à alimentação é um direito de todos os cidadãos, a ser garantido por meio de políticas públicas de Segurança Alimentar e Nutricional (SAN), que, por sua vez, são uma responsabilidade do Estado e da sociedade.

O direito à alimentação é o direito de todos ao acesso regular e permanente a alimentos de qualidade, em quantidade suficiente. Sua base tem práticas alimentares promotoras da saúde que respeitam os aspectos ambientais, culturais, econômicos e sociais (Lei n. 11.346/2006) ${ }^{9}$. Por essa razão, assegurar a alimentação significa assegurar o direito elementar à vida ${ }^{10}$.

Maia e Baracho ${ }^{11}$, ao defenderem os direitos sociais, justificam sua importância como direitos fundamentais e argumentam que tais direitos se encontram positivados no título II da CF/88. Contudo, mesmo reconhecendo a força normativa dos enunciados constitucionais, que se deu com o constitucionalismo contemporâneo no desenvolvimento da doutrina brasileira da efetividade, o campo do direito parece não se preocupar com o estudo da efetividade do DHAA na realidade concreta.

$\mathrm{O}$ reconhecimento dos direitos sociais e a luta para a garantia de sua efetivação estão pautados nas relações sociais existentes. Resultado de lutas sociais que vêm ocorrendo há séculos, trata-se de uma forma de a sociedade se posicionar soberana e contrariamente a qualquer tipo de exclusão, discriminação e opressão, disputando o poder em busca da transformação social ${ }^{12}$.

Quando se fala sobre "efetividade jurídica", considera-se que este termo esteja relacionado à capacidade da norma de ser efetivada tanto pelos destinatários quanto pelos aplicadores do ordenamento. Assim, para que se possa falar em efetividade, o Estado deve atuar não simplesmente editando leis, mas também aumentando a densidade das normas instituidoras de direitos sociais por meio da realização de políticas públicas de direito ${ }^{13}$.

\footnotetext{
${ }^{6}$ NUNES, Mercés da Silva. O direito fundamental à alimentação e o princípio da segurança. Rio de Janeiro: Elsevier, 2008.

${ }^{7}$ ARRUDA, IIma K. G. de; ARRUDA, Bertoldo K. G. de. Nutrição e desenvolvimento. Cad. Saúde Pública, Rio de Janeiro, v. 10, n. 3, p. 392-397, set. 1994. Disponível em: http://www.scielo.br/pdf/csp/v10n3/v10n3a19. pdf. https://doi.org/10.1590/S0102-311X1994000300019..

${ }^{8}$ VALENTE, Flávio Luiz Schieck. Direito humano à alimentação: desafios e conquistas. São Paulo: Editora Cortez, 2002.

${ }^{9}$ BRASIL. Lei n. 11.346, de 15 de setembro de 2006. Cria o Sistema Nacional de Segurança Alimentar e Nutricional - SISAN com vistas em assegurar o direito humano à alimentação adequada e dá outras providências. Disponível em: http://www.planalto.gov.br/ccivil_03/_ato2004-2006/2006/lei/l11346.htm. Acesso em: 21 abr. 2021.

${ }^{10}$ MALUF, Renato S. Segurança alimentar e nutricional. 2. ed. Rio de Janeiro: Vozes, 2009.

${ }^{11}$ MAIA, M.S.F.; BARACHO, H.U.A. A efetividade dos direitos sociais no Brasil: comentários sobre o papel do Judiciário. 2007. p. 53-68. Disponível em: http://periodicos.ufpb.br/index.php/primafacie/article/ viewFile/6535/4098. Acesso em: 01 abr. 2019.

${ }^{12}$ GUERRA, Lúcia Dias da Silva. Direito humano à alimentação adequada e atuação profissional em saúde pública. Tese (Doutorado) - Programa de Pós-Graduação de Nutrição em Saúde Pública da Faculdade de Saúde Pública da Universidade de São Paulo, 2017. Disponível em: https://teses.usp.br/teses/ disponiveis/6/6138/tde-29112017-001605/publico/LuciaDiasdaSilvaGuerraRevisada.pdf.

${ }^{13}$ Id. Ibid.
} 
Contudo, o que se percebe é que a omissão estatal na execução das normas de direitos fundamentais tem sido frequente, sendo necessária uma visão crítica a respeito da eficácia dessas normas, que nem sempre são suficientes para reduzir efetivamente as desigualdades sociais. Parece ser mais nesse sentido que os estudos sobre a efetividade do DHAA são desenvolvidos por áreas do conhecimento que apreendem a política social como algo mais amplo, como é o caso da área da saúde coletiva.

Levando-se em conta que o estudo da efetividade jurídica dos direitos sociais necessita de atualização constante, este estudo visa a compreender como a efetividade do direito à alimentação é abordada na produção científica tanto na área do direito quanto na da saúde coletiva. O intuito é fortalecer o constitucionalismo contemporâneo, identificando as lacunas de estudo sobre os direitos ditos fundamentais dos cidadãos com vistas a aumentar sua efetivação concreta e cotidiana.

\section{Método}

O estudo é de abordagem qualitativa ${ }^{14}$, realizado por meio de análise de conteúdo, de foco lexical ${ }^{15}$, da produção científica nas áreas do direito e da saúde coletiva sobre a efetividade do DHAA. Para isso, foram utilizados dois procedimentos metodológicos: o primeiro tratou-se de uma revisão sistematizada da produção científica $^{16,17,18,19}$, a partir da coleta em periódicos das áreas do direito e da saúde coletiva que publicam sobre os direitos sociais e humanos. Como critério, utilizou-se a presença dos termos "social(ais)" ou "humano(s)" no nome dos periódicos; quando o nome do periódico não tinha nenhum destes termos, leu-se o escopo da revista para identificar se elas têm ênfase na produção de conhecimento sobre os direitos sociais e humanos.

O parâmetro para identificar a produção científica nos periódicos e fazer o filtro necessário sobre seus escopos foi a classificação do Qualis Capes (quadriênio

\footnotetext{
${ }^{14}$ BAUER, Martin W; GASKELL, George. Pesquisa qualitativa com texto, imagem e som: um manual prático. Rio de Janeiro: Vozes, 2002.

${ }^{15}$ NASCIMENTO, Adriano Roberto Afonso do; MENANDRO, Paulo Rogério Meira. Análise lexical e análise de conteúdo: uma proposta de utilização conjugada. Estudos e Pesquisas em Psicologia, UERJ, Rio de Janeiro, v. 6, n. 2, p. 72-88, dez. 2006. Disponível em: http://pepsic.bvsalud.org/pdf/epp/v6n2/v6n2a07.pdf.

${ }^{16}$ HATAB, Assem Abu; CAVINATO, Maria Eduarda Rigo; LINDEMER, August; LAGERKVIST, Carl-Johan. Urban sprawl, food security and agricultural systems in developing countries: a systematic review of the literature. Cities, v. 24, p. 129-142, Nov. 2019. Disponível em: https://www.sciencedirect.com/science/ article/pii/S0264275118310485/pdfft?md5=60574f9be6fd6c0e8674704de0f8f45f\&pid=1-s2.0S0264275118310485-main.pdf. https://doi.org/10.1016/j.cities.2019.06.001.

${ }^{17}$ CULLERTON, Katherine; ADAMS, Jeans; FOROUHI, Nita; FRANCIS, Oliver; WHITE, Martin. What principles should guide interactions between population health researchers and the food industry? Systematic scoping review of peer-reviewed and grey literature. Obes Rev., v. 20, n. 8, p.1073-1084, Aug. 2019. http:// dx.doi.org/10.1111/obr.12851.

${ }^{18} \mathrm{KOKABISAGHI}$, Fatemeh. Assessment of the effects of economic sanctions on Iranian's right to health by using human rights impact assessment tool: a systematic review. Int J Health Policy Manag, v. 7, n. 5, p. 374-393, May 2018. https://doi.org/10.15171/ijhpm.2017.147.

${ }^{19}$ HIGGINS, Julian; GREEN, Sally. Cochrane handbook for systematic reviews of interventions. Version 5.1.0. Mar 2011. Editors: Julian PT Higgins, Sally Green. Oxford, UK: Cochrane Collaboration, 2011. Disponível em: https://handbook-5-1.cochrane.org/.
} 
2013-2016) para as áreas do direito e da saúde coletiva, disponível no site da Plataforma Sucupira ${ }^{20}$. Após listar as revistas classificadas, nas duas áreas separadamente, foram identificadas aquelas que se dedicam a publicar artigos sobre direitos sociais e humanos. Assim, de acordo com a área de avaliação que interessava à pesquisa (direito e saúde coletiva), foi obtida uma lista de periódicos em arquivo XLS.

Após o download desta lista em arquivo XLS, foi utilizado o recurso de filtro (no Excel) a fim de obter somente os títulos de periódicos no idioma português e com os seguintes termos presentes nos títulos: "human*”; "social". Depois dessa filtragem, identificaram-se os periódicos que publicam artigos sobre direitos sociais e humanos (Quadro 1). Quando havia dúvida, lia-se o escopo do periódico em seu próprio site. $\mathrm{O}$ mesmo procedimento foi realizado com os periódicos classificados na área da saúde coletiva. Foram excluídos aqueles periódicos que já tinham entrado na classificação para a área do direito e que se repetiam na saúde coletiva (pois eram classificados para ambas as áreas), mantendo-se apenas uma aparição desses títulos.

Após esta etapa, foi utilizado o sistema de busca da própria revista para identificar se havia publicações sobre a efetividade do DHAA. Devido à especificidade do termo, os seguintes termos foram buscados: "segurança alimentar"; "direito" and "alimentação"; "fome"; "aliment*”; "nutri*”; encontrados no título ou no assunto, por intersecção de termos. No Quadro 1 são apresentados os manuscritos e as revistas identificados na busca.

Quadro 1. Manuscritos identificados em periódicos das áreas do direito e da saúde coletiva que tratavam de direitos sociais e humanos, seus respectivos autores e classificação dos periódicos. Abril, 2018.

\begin{tabular}{|l|l|l|l|}
\hline $\begin{array}{l}\text { Grande } \\
\text { área }\end{array}$ & $\begin{array}{l}\text { Qualis Capes } \\
\mathbf{2 0 1 6 - 2 0 1 9}\end{array}$ & \multicolumn{1}{|c|}{ Autores } & \multicolumn{1}{c|}{ Título } \\
\hline Direito & A2 & Shetty, S. & $\begin{array}{l}\text { Declaração e Objetivos de Desenvolvimento } \\
\text { do Milênio: oportunidades para os } \\
\text { direitos humanos. }\end{array}$ \\
\hline Direito & A2 & Zimmermann, C.R. & $\begin{array}{l}\text { Os programas sociais sob a ótica dos } \\
\text { direitos humanos: o caso do Bolsa Família } \\
\text { do governo Lula no Brasil }\end{array}$ \\
\hline Direito & B4 & $\begin{array}{l}\text { Prado-Netto, A.; Marques, } \\
\text { T.G.; Prado-Netto, G. }\end{array}$ & $\begin{array}{l}\text { Aquisição gustativa na infância: teoria } \\
\text { e estudos }\end{array}$ \\
\hline Direito & C & Menezes, F & $\begin{array}{l}\text { Segurança alimentar: direito humano } \\
\text { à alimentação }\end{array}$ \\
\hline Direito & C & $\begin{array}{l}\text { Freitas, El.; Clementino, } \\
\text { M.B.M.; Lima, R.S. }\end{array}$ & $\begin{array}{l}\text { Políticas para crianças e adolescentes e } \\
\text { a relevância do profissional de nutrição } \\
\text { em abrigos }\end{array}$ \\
\hline
\end{tabular}

${ }^{20}$ COORDENAÇÃO DE APERFEIÇOAMENTO DE PESSOAL DE NÍVEL SUPERIOR - CAPES. Plataforma Sucupira. Disponível em: https://sucupira.capes.gov.br. 
Continuação

\begin{tabular}{|c|c|c|c|}
\hline $\begin{array}{l}\text { Grande } \\
\text { área }\end{array}$ & $\begin{array}{c}\text { Qualis Capes } \\
2016-2019\end{array}$ & Autores & Título \\
\hline Direito & C & Marques Junior, J.S. & $\begin{array}{l}\text { Políticas de Ação Afirmativa para Negros no } \\
\text { Brasil: elementos para uma reflexão inicial } \\
\text { no Serviço Social }\end{array}$ \\
\hline Direito & C & Silva, A.M. & Do combate à fome à seguridade alimentar \\
\hline Direito & $\mathrm{C}$ & Baccarin, G. & $\begin{array}{l}\text { Políticas públicas continuadas: a garantia de } \\
\text { segurança alimentar }\end{array}$ \\
\hline Direito & C & Betto, F. & $\begin{array}{l}\text { Fome e pobreza: problemas sociais e } \\
\text { questões políticas }\end{array}$ \\
\hline Direito & C & Andrade, $\mathrm{M}$. & $\begin{array}{l}\text { Fome, cidadania e polêmicas hipócritas: } \\
\text { as responsabilidades do Estado e da } \\
\text { sociedade civil }\end{array}$ \\
\hline Direito & C & Belik, W. & Fome Zero: um guarda-chuva de iniciativas \\
\hline Direito & C & Brugger, A.S. & $\begin{array}{l}\text { Judicialização da vida: o cenário das mulheres } \\
\text { e breves anotações sobre supremacia judicial } \\
\text { e supremacia constitucional }\end{array}$ \\
\hline Direito & C & $\begin{array}{l}\text { Alves, J.M.; Almeida, } \\
\text { D.M.F. }\end{array}$ & $\begin{array}{l}\text { Participação e controle social: a experiência } \\
\text { do Conselho Municipal de Assistência Social } \\
\text { de Londrina/PR }\end{array}$ \\
\hline Direito & C & Campos, B.P.C. & $\begin{array}{l}\text { A trajetória da implementação de sentenças } \\
\text { da corte interamericana de direitos } \\
\text { humanos no Brasil }\end{array}$ \\
\hline $\begin{array}{l}\text { Saúde } \\
\text { coletiva }\end{array}$ & A2 & $\begin{array}{l}\text { Silva, E.K.P.; Medeiros, } \\
\text { D.S.; Martins, P.C.; } \\
\text { Sousa, L.A.; Lima, G.P.; } \\
\text { Rêgo, M.A.S. et al. }\end{array}$ & $\begin{array}{l}\text { Insegurança alimentar em comunidades } \\
\text { rurais no Nordeste brasileiro: faz diferença } \\
\text { ser quilombola? }\end{array}$ \\
\hline $\begin{array}{l}\text { Saúde } \\
\text { coletiva }\end{array}$ & A2 & $\begin{array}{l}\text { Machado, M.L.; Gabriel, } \\
\text { C.G.; Soar, C.; Mamed, } \\
\text { G.R.; Machado, P.M.O.; } \\
\text { Lacerda, J.T. et al. }\end{array}$ & $\begin{array}{l}\text { Adequação normativa dos planos estaduais } \\
\text { de segurança alimentar e nutricional } \\
\text { no Brasil }\end{array}$ \\
\hline $\begin{array}{l}\text { Saúde } \\
\text { coletiva }\end{array}$ & A2 & $\begin{array}{l}\text { Vasconcellos, A.B.P.A.; } \\
\text { Moura, L.B.A. }\end{array}$ & $\begin{array}{l}\text { Segurança alimentar e nutricional: uma } \\
\text { análise da situação da descentralização de } \\
\text { sua política pública nacional }\end{array}$ \\
\hline $\begin{array}{l}\text { Saúde } \\
\text { coletiva }\end{array}$ & A2 & $\begin{array}{l}\text { Santos, T.G.; Silveira, } \\
\text { J.A.C.; Longo-Silva, G.; } \\
\text { Ramires, E.K.N.M.; } \\
\text { Menezes, R.C.E. }\end{array}$ & $\begin{array}{l}\text { Tendência e fatores associados à } \\
\text { insegurança alimentar no Brasil: Pesquisa } \\
\text { Nacional por Amostra de Domicílios 2004, } \\
2009 \text { e } 2013\end{array}$ \\
\hline $\begin{array}{l}\text { Saúde } \\
\text { coletiva }\end{array}$ & A2 & $\begin{array}{l}\text { Neves-Silva, P.; Martins, } \\
\text { G.I.; Heller, L. }\end{array}$ & $\begin{array}{l}\text { “A gente tem acesso de favores, né?”. A } \\
\text { percepção de pessoas em situação de rua } \\
\text { sobre os direitos humanos à água e ao } \\
\text { esgotamento sanitário }\end{array}$ \\
\hline $\begin{array}{l}\text { Saúde } \\
\text { coletiva }\end{array}$ & A2 & $\begin{array}{l}\text { Silva, E.O.; } \\
\text { Amparo-Santos, L.; } \\
\text { Soares, M.D. }\end{array}$ & $\begin{array}{l}\text { Alimentação escolar e constituição de } \\
\text { identidades dos escolares: da merenda para } \\
\text { pobres ao direito à alimentação }\end{array}$ \\
\hline
\end{tabular}


Continuação

\begin{tabular}{|c|c|c|c|}
\hline $\begin{array}{l}\text { Grande } \\
\text { área }\end{array}$ & $\begin{array}{c}\text { Qualis Capes } \\
2016-2019\end{array}$ & Autores & Título \\
\hline $\begin{array}{l}\text { Saúde } \\
\text { coletiva }\end{array}$ & B4 & Dias, P.R.P. & $\begin{array}{l}\text { Direito à Saúde: demanda por suplementos } \\
\text { alimentares no Tribunal de Justiça de } \\
\text { Minas Gerais }\end{array}$ \\
\hline $\begin{array}{l}\text { Saúde } \\
\text { coletiva }\end{array}$ & B4 & Azevedo, J.L. & $\begin{array}{l}\text { O modelo industrial de produção de } \\
\text { alimentos sob a perspectiva da sociedade } \\
\text { de risco e do princípio da precaução }\end{array}$ \\
\hline $\begin{array}{l}\text { Saúde } \\
\text { coletiva }\end{array}$ & B4 & $\begin{array}{l}\text { Silva, C.E.G.; Silva, } \\
\text { R.S.R.D.; Pimenta, P.M.C.; } \\
\text { Chaves, N.S.; Castro, } \\
\text { L.M.C.; Soares, E.A. et al. }\end{array}$ & $\begin{array}{l}\text { Proposta de cesta básica para a população } \\
\text { da região metropolitana do Rio de Janeiro e } \\
\text { sua relação com salário-mínimo vigente }\end{array}$ \\
\hline $\begin{array}{l}\text { Saúde } \\
\text { coletiva }\end{array}$ & B1 & $\begin{array}{l}\text { Pinheiro, A.R.O.; } \\
\text { Carvalho, M.F.C.C. }\end{array}$ & $\begin{array}{l}\text { Transformando o problema da fome em } \\
\text { questão alimentar e nutricional: uma crônica } \\
\text { desigualdade social }\end{array}$ \\
\hline $\begin{array}{l}\text { Saúde } \\
\text { coletiva }\end{array}$ & B1 & Burlandy, L.; Labra, M.E. & $\begin{array}{l}\text { Redes de Política no Combate à Fome e à } \\
\text { Pobreza. A Estratégia Comunidade Solidária } \\
\text { no Brasil }\end{array}$ \\
\hline $\begin{array}{l}\text { Saúde } \\
\text { coletiva }\end{array}$ & B1 & $\begin{array}{l}\text { Martinelli, S.S.; } \\
\text { Cavalli, S.B. }\end{array}$ & $\begin{array}{l}\text { Alimentação saudável e sustentável: } \\
\text { Uma revisão narrativa sobre desafios e } \\
\text { perspectivas }\end{array}$ \\
\hline $\begin{array}{l}\text { Saúde } \\
\text { coletiva }\end{array}$ & B2 & $\begin{array}{l}\text { Oliveira, K.S.; Silva, D.O.; } \\
\text { Souza, W.V. }\end{array}$ & $\begin{array}{l}\text { Barreiras percebidas por médicos do } \\
\text { Distrito Federal para a promoção da } \\
\text { alimentação saudável }\end{array}$ \\
\hline $\begin{array}{l}\text { Saúde } \\
\text { coletiva }\end{array}$ & B2 & $\begin{array}{l}\text { Vieira, C.M.; Santiago, L.S.; } \\
\text { Tavare, P.C.W.; Brandt, A.; } \\
\text { Negri, F.; Oliveira M.R.M. }\end{array}$ & $\begin{array}{l}\text { Aplicação da técnica de grupo focal em pesquisa } \\
\text { da Rede-SANS sobre as ações de alimentação e } \\
\text { nutrição na atenção básica em saúde }\end{array}$ \\
\hline $\begin{array}{l}\text { Saúde } \\
\text { coletiva }\end{array}$ & B1 & Alves, K.P.S.; Jaime, P.C. & $\begin{array}{l}\text { A Política Nacional de alimentação e } \\
\text { Nutrição e seu diálogo com a Política } \\
\text { Nacional de Segurança alimentar e } \\
\text { Nutricional }\end{array}$ \\
\hline $\begin{array}{l}\text { Saúde } \\
\text { coletiva }\end{array}$ & B1 & $\begin{array}{l}\text { Gubert, M.B.; Perez- } \\
\text { Escamilla, R. }\end{array}$ & $\begin{array}{l}\text { Insegurança alimentar grave municipal no } \\
\text { Brasil em } 2013\end{array}$ \\
\hline $\begin{array}{l}\text { Saúde } \\
\text { coletiva }\end{array}$ & B1 & Silva, M.F.S.; Nunes, E.D. & $\begin{array}{l}\text { Josué de Castro e o pensamento } \\
\text { social brasileiro }\end{array}$ \\
\hline $\begin{array}{l}\text { Saúde } \\
\text { coletiva }\end{array}$ & B1 & $\begin{array}{l}\text { Ramos, C.I.; } \\
\text { Cuervo, M.R.M. }\end{array}$ & $\begin{array}{l}\text { Programa Bolsa Família: a interface entre } \\
\text { a atuação profissional e o direito humano a } \\
\text { alimentação adequada }\end{array}$ \\
\hline $\begin{array}{l}\text { Saúde } \\
\text { coletiva }\end{array}$ & B1 & $\begin{array}{l}\text { Santos, C.R.B.; } \\
\text { Magalhães, R. }\end{array}$ & $\begin{array}{l}\text { Pobreza e Política Social: a implementação } \\
\text { de programas complementares do Programa } \\
\text { Bolsa Família }\end{array}$ \\
\hline $\begin{array}{l}\text { Saúde } \\
\text { coletiva }\end{array}$ & B1 & $\begin{array}{l}\text { Casemiro, J.P.; Valla, V.V.; } \\
\text { Guimarães, M.B.L. }\end{array}$ & $\begin{array}{l}\text { Direito humano à alimentação adequada: } \\
\text { um olhar urbano }\end{array}$ \\
\hline $\begin{array}{l}\text { Saúde } \\
\text { coletiva }\end{array}$ & B1 & $\begin{array}{l}\text { Gomes, M.A.; } \\
\text { Pereira, M.L.D. }\end{array}$ & $\begin{array}{l}\text { Família em situação de vulnerabilidade } \\
\text { social: uma questão de políticas públicas }\end{array}$ \\
\hline
\end{tabular}


Continuação

\begin{tabular}{|c|c|c|c|}
\hline $\begin{array}{l}\text { Grande } \\
\text { área }\end{array}$ & $\begin{array}{l}\text { Qualis Capes } \\
2016-2019\end{array}$ & Autores & Título \\
\hline $\begin{array}{l}\text { Saúde } \\
\text { coletiva }\end{array}$ & B1 & $\begin{array}{l}\text { Coimbra Jr, C.E.A.; } \\
\text { Santos, R.V. }\end{array}$ & $\begin{array}{l}\text { Saúde, minorias e desigualdade: algumas } \\
\text { teias de inter-relações, com ênfase nos } \\
\text { povos indígenas no Brasil }\end{array}$ \\
\hline $\begin{array}{l}\text { Saúde } \\
\text { coletiva }\end{array}$ & B1 & $\begin{array}{l}\text { Jaime, P.C.; Delmuè, } \\
\text { D.C.C.; Campello, T.; } \\
\text { Silva, D.O.; Santos, L.M.P. }\end{array}$ & $\begin{array}{l}\text { Um olhar sobre a agenda de alimentação e } \\
\text { nutrição nos trinta anos do Sistema Único } \\
\text { de Saúde }\end{array}$ \\
\hline $\begin{array}{l}\text { Saúde } \\
\text { coletiva }\end{array}$ & B1 & $\begin{array}{l}\text { Almeida, J.A.; Santos, } \\
\text { A.S.; Nascimento, M.A.O.; } \\
\text { Oliveira, J.V.C.; Silva, } \\
\text { D.G.; Mendes-Netto, R.S. }\end{array}$ & $\begin{array}{l}\text { Fatores associados ao risco de insegurança } \\
\text { alimentar e nutricional em famílias de } \\
\text { assentamentos rurais }\end{array}$ \\
\hline $\begin{array}{l}\text { Saúde } \\
\text { coletiva }\end{array}$ & B1 & Vasconcelos, F.A.G. & $\begin{array}{l}\text { Programa Nacional de Alimentação } \\
\text { Escolar: limites e possibilidades para a } \\
\text { garantia do direito humano à alimentação } \\
\text { adequada, saudável e sustentável }\end{array}$ \\
\hline $\begin{array}{l}\text { Saúde } \\
\text { coletiva }\end{array}$ & B1 & $\begin{array}{l}\text { Siqueira, R.L.; Cotta, } \\
\text { R.M.M.; Ribeiro, R.C.L.; } \\
\text { Sperandio, N.; Priore, S.E. }\end{array}$ & $\begin{array}{l}\text { Análise da incorporação da perspectiva do } \\
\text { direito humano à alimentação adequada no } \\
\text { desenho institucional do programa nacional } \\
\text { de alimentação escolar }\end{array}$ \\
\hline $\begin{array}{l}\text { Saúde } \\
\text { coletiva }\end{array}$ & B1 & $\begin{array}{l}\text { Lang, R.M.F.; Almeida, } \\
\text { C.C.B.; Taddei, J.A.A.C. }\end{array}$ & $\begin{array}{l}\text { Segurança alimentar e nutricional de } \\
\text { crianças menores de dois anos de famílias } \\
\text { de trabalhadores rurais Sem Terra }\end{array}$ \\
\hline $\begin{array}{l}\text { Saúde } \\
\text { coletiva }\end{array}$ & B1 & Bosi, M.L.M. & $\begin{array}{l}\text { Desafios na interface pesquisa-construção } \\
\text { do direito humano à alimentação: reflexões } \\
\text { no âmbito da segurança alimentar e } \\
\text { nutricional }\end{array}$ \\
\hline $\begin{array}{l}\text { Saúde } \\
\text { coletiva }\end{array}$ & B4 & $\begin{array}{l}\text { Ribeiro, G.; Morais, } \\
\text { F.M.O.; Pinho, L. }\end{array}$ & $\begin{array}{l}\text { (In) segurança alimentar de comunidade } \\
\text { quilombola no norte de Minas Gerais }\end{array}$ \\
\hline $\begin{array}{l}\text { Saúde } \\
\text { coletiva }\end{array}$ & B4 & Silva, A.G.; Curioni, C.C. & $\begin{array}{l}\text { Insegurança alimentar e fatores associados } \\
\text { em beneficiários de programas sociais de } \\
\text { combate à fome no município de Petrópolis- } \\
\text { RJ, Brasil }\end{array}$ \\
\hline $\begin{array}{l}\text { Saúde } \\
\text { coletiva }\end{array}$ & B4 & $\begin{array}{l}\text { Ribeiro, C.S.G.; } \\
\text { Pilla, M.C.B.A. }\end{array}$ & $\begin{array}{l}\text { Segurança alimentar e nutricional: interfaces } \\
\text { e diminuição de desigualdades sociais }\end{array}$ \\
\hline $\begin{array}{l}\text { Saúde } \\
\text { coletiva }\end{array}$ & B4 & $\begin{array}{l}\text { Schattschneider, D.P.; } \\
\text { Ruiz, E.N.F.; Escobar, M.Z. }\end{array}$ & $\begin{array}{l}\text { Acesso aos alimentos no território de } \\
\text { uma unidade de saúde: um enfoque } \\
\text { multidimensional }\end{array}$ \\
\hline $\begin{array}{l}\text { Saúde } \\
\text { coletiva }\end{array}$ & C & $\begin{array}{l}\text { Silva, A.C.P.; Garcia, G.A.; } \\
\text { Oliveira, L.F.; Oliveira, A.P.P. }\end{array}$ & $\begin{array}{l}\text { Políticas Públicas e Segurança Alimentar: } \\
\text { Análise do Programa de Aquisição de } \\
\text { Alimentos (PAA) no Estado do Pará }\end{array}$ \\
\hline $\begin{array}{l}\text { Saúde } \\
\text { coletiva }\end{array}$ & C & $\begin{array}{l}\text { Fuzeto, K.L.R.; } \\
\text { Lang, R.M.F. }\end{array}$ & $\begin{array}{l}\text { Promoção de Práticas Alimentares } \\
\text { Saudáveis: Contribuição Para a Garantia } \\
\text { da Segurança Alimentar e Nutricional no } \\
\text { Município de Curitiba-Paraná }\end{array}$ \\
\hline
\end{tabular}


Continuação

\begin{tabular}{|c|c|c|c|}
\hline $\begin{array}{l}\text { Grande } \\
\text { área }\end{array}$ & $\begin{array}{c}\text { Qualis Capes } \\
2016-2019\end{array}$ & Autores & Título \\
\hline $\begin{array}{l}\text { Saúde } \\
\text { coletiva }\end{array}$ & B5 & Filgueiras, C.A.C. & $\begin{array}{l}\text { Insegurança, desperdício e ajuda alimentar } \\
\text { na Europa do século XXI }\end{array}$ \\
\hline $\begin{array}{l}\text { Saúde } \\
\text { coletiva }\end{array}$ & B5 & $\begin{array}{l}\text { Schmitz, H.; Mota, D.M.; } \\
\text { Sousa, G.M. }\end{array}$ & $\begin{array}{l}\text { O fim do Programa de Aquisição de } \\
\text { Alimentos: reviravoltas para mulheres } \\
\text { extrativistas em Sergipe }\end{array}$ \\
\hline $\begin{array}{l}\text { Saúde } \\
\text { coletiva }\end{array}$ & B5 & $\begin{array}{l}\text { Traldi, D.R.C.; } \\
\text { Almeida, L.M.M.C. }\end{array}$ & $\begin{array}{l}\text { Políticas públicas de transferência de renda } \\
\text { e a questão da segurança alimentar dos } \\
\text { beneficiários: efetividades e entraves do } \\
\text { Programa Bolsa Família. }\end{array}$ \\
\hline $\begin{array}{l}\text { Saúde } \\
\text { coletiva }\end{array}$ & B5 & $\begin{array}{l}\text { Moura, J.T.V.; } \\
\text { Monteiro, L.M. }\end{array}$ & $\begin{array}{l}\text { Democratização ou assimetria da } \\
\text { representação: notas sobre os Conselhos } \\
\text { Estaduais de Segurança Alimentar e } \\
\text { Nutricional }\end{array}$ \\
\hline $\begin{array}{l}\text { Saúde } \\
\text { coletiva }\end{array}$ & B3 & $\begin{array}{l}\text { Suzart, A.S.; Ferreira, } \\
\text { A.P.; Lemos, G.C.S.M.; } \\
\text { Correa, G.T.B.; Bonfatti, } \\
\text { R.J.; Oliveira, M.H.B. }\end{array}$ & $\begin{array}{l}\text { Repercussões do programa bolsa família } \\
\text { na segurança alimentar e nutricional: um } \\
\text { estudo de caso }\end{array}$ \\
\hline $\begin{array}{l}\text { Saúde } \\
\text { coletiva }\end{array}$ & B3 & $\begin{array}{l}\text { Oliveira, D.S.; Demétrio, } \\
\text { F.; Soares, M.D.; } \\
\text { Henrique, F.C.S.; Amparo- } \\
\text { Santos, L. }\end{array}$ & $\begin{array}{l}\text { Prevalência e fatores associados à } \\
\text { insegurança alimentar }\end{array}$ \\
\hline $\begin{array}{l}\text { Saúde } \\
\text { coletiva }\end{array}$ & B3 & $\begin{array}{l}\text { Pereira, S.M.P.D.; Brito, } \\
\text { L.A.M.H.; Palácio, M.A.V.; } \\
\text { Monteiro, M.P.A. }\end{array}$ & $\begin{array}{l}\text { Operacionalização do sistema de vigilância } \\
\text { alimentar e nutricional em Juazeiro do Norte, } \\
\text { Ceará }\end{array}$ \\
\hline $\begin{array}{l}\text { Saúde } \\
\text { coletiva }\end{array}$ & B3 & $\begin{array}{l}\text { Alves, F.R.; Alves, S.R.; } \\
\text { Garófolo, A.; Modesto, } \\
\text { P.C. }\end{array}$ & $\begin{array}{l}\text { Binômio desnutrição e pobreza: uma } \\
\text { meta a ser vencida pelos países em } \\
\text { desenvolvimento }\end{array}$ \\
\hline $\begin{array}{l}\text { Saúde } \\
\text { coletiva }\end{array}$ & B4 & $\begin{array}{l}\text { Lemos, J.O.M.; } \\
\text { Moreira, P.V.L. }\end{array}$ & $\begin{array}{l}\text { Políticas e programas de alimentação e } \\
\text { nutrição: um passeio pela história }\end{array}$ \\
\hline $\begin{array}{l}\text { Saúde } \\
\text { coletiva }\end{array}$ & B4 & Walker, P.B. & $\begin{array}{l}\text { A construção do Direito ao Desenvolvimento } \\
\text { e sua aplicação mediante as políticas } \\
\text { públicas de sustentabilidade }\end{array}$ \\
\hline $\begin{array}{l}\text { Saúde } \\
\text { coletiva }\end{array}$ & B4 & Franco, R. & $\begin{array}{l}\text { Direito agroalimentar e território: reflexões } \\
\text { sobre o uso da água na atividade agrícola }\end{array}$ \\
\hline $\begin{array}{l}\text { Saúde } \\
\text { coletiva }\end{array}$ & B4 & Muniz, V.C. & $\begin{array}{l}\text { Desenvolvimento humano sustentável } \\
\text { e erradicação da pobreza extrema: uma } \\
\text { análise sobre a experiência portuguesa }\end{array}$ \\
\hline $\begin{array}{l}\text { Saúde } \\
\text { coletiva }\end{array}$ & B4 & Amorim, R.L.C. & $\begin{array}{l}\text { A construção de novas políticas sociais: o } \\
\text { caso de Mato Grosso do Sul }\end{array}$ \\
\hline $\begin{array}{l}\text { Saúde } \\
\text { coletiva }\end{array}$ & C & $\begin{array}{l}\text { Machado, N.M.V.; } \\
\text { Machado, P.M.O.; } \\
\text { Ramos, C.; Matielo, E. }\end{array}$ & $\begin{array}{l}\text { Tenda Josué de Castro - uma homenagem a } \\
\text { um dos precursores do debate sobre fome e } \\
\text { segurança alimentar e nutricional no Brasil } \\
\text { e no mundo }\end{array}$ \\
\hline
\end{tabular}


Continuação

\begin{tabular}{|c|c|c|c|}
\hline $\begin{array}{l}\text { Grande } \\
\text { área }\end{array}$ & \begin{tabular}{|c|} 
Qualis Capes \\
$2016-2019$ \\
\end{tabular} & Autores & Título \\
\hline $\begin{array}{l}\text { Saúde } \\
\text { coletiva }\end{array}$ & C & $\begin{array}{l}\text { Mancuso, A.M.C.; } \\
\text { Coelho, D.E.P.; Vieira, V.L. }\end{array}$ & $\begin{array}{l}\text { Segurança alimentar e nutricional: } \\
\text { percepções de coordenadores de cursos de } \\
\text { nutrição }\end{array}$ \\
\hline $\begin{array}{l}\text { Saúde } \\
\text { coletiva }\end{array}$ & B3 & Rocha, E.G. & $\begin{array}{l}\text { A construção democrática do direito à } \\
\text { alimentação adequada e a regulação de } \\
\text { alimentos }\end{array}$ \\
\hline $\begin{array}{l}\text { Saúde } \\
\text { coletiva }\end{array}$ & B3 & Magalhães, R. & Regulação de alimentos no Brasil \\
\hline $\begin{array}{l}\text { Saúde } \\
\text { coletiva }\end{array}$ & B3 & Teixeira, T.M. & $\begin{array}{l}\text { Saúde e direito à informação: o problema } \\
\text { dos agrotóxicos nos alimentos }\end{array}$ \\
\hline $\begin{array}{l}\text { Saúde } \\
\text { coletiva }\end{array}$ & B3 & Baptista, P.; Dionisio, P.H. & $\begin{array}{l}\text { O Direito Administrativo do risco: a nova } \\
\text { intervenção estatal sob o enfoque da } \\
\text { segurança alimentar }\end{array}$ \\
\hline $\begin{array}{l}\text { Saúde } \\
\text { coletiva }\end{array}$ & B3 & $\begin{array}{l}\text { Fagundes, M.J.D.; } \\
\text { Souza, R.F. }\end{array}$ & $\begin{array}{l}\text { A publicidade de alimentos e o direito à } \\
\text { saúde }\end{array}$ \\
\hline $\begin{array}{l}\text { Saúde } \\
\text { coletiva }\end{array}$ & B3 & $\begin{array}{l}\text { Tancredi, R.C.P.; Barreto, } \\
\text { A.F.; Tancredi, J.G.R. }\end{array}$ & $\begin{array}{l}\text { Direito e saúde: a discricionariedade nas } \\
\text { ações fiscais da vigilância sanitária de } \\
\text { alimentos }\end{array}$ \\
\hline $\begin{array}{l}\text { Saúde } \\
\text { coletiva }\end{array}$ & B3 & Custódio, H.B. & $\begin{array}{l}\text { Direito à saúde e problemática dos } \\
\text { agrotóxicos }\end{array}$ \\
\hline $\begin{array}{l}\text { Saúde } \\
\text { coletiva }\end{array}$ & B2 & Albuquerque, M.F.M. & $\begin{array}{l}\text { A segurança alimentar e nutricional e o } \\
\text { uso da abordagem de direitos humanos } \\
\text { no desenho das políticas públicas para } \\
\text { combater a fome e a pobreza. }\end{array}$ \\
\hline $\begin{array}{l}\text { Saúde } \\
\text { coletiva }\end{array}$ & B2 & $\begin{array}{l}\text { Coelho, A.I.M.; Campos, } \\
\text { M.T.F.S.; Lopes, M.L.M.; } \\
\text { Novaes, J.F. }\end{array}$ & $\begin{array}{l}\text { Dia Mundial da Alimentação: duas décadas } \\
\text { no combate aos problemas alimentares } \\
\text { mundiais }\end{array}$ \\
\hline $\begin{array}{l}\text { Saúde } \\
\text { coletiva }\end{array}$ & B2 & Vasconcelos, F.A.G. & $\begin{array}{l}\text { Combate à fome no Brasil: uma análise } \\
\text { histórica de Vargas a Lula }\end{array}$ \\
\hline $\begin{array}{l}\text { Saúde } \\
\text { coletiva }\end{array}$ & C & $\begin{array}{l}\text { Ávila, M.M.M.; } \\
\text { Costa, M.C.O. }\end{array}$ & $\begin{array}{l}\text { A participação social e o direito humano à } \\
\text { alimentação adequada no contexto brasileiro }\end{array}$ \\
\hline $\begin{array}{l}\text { Saúde } \\
\text { coletiva }\end{array}$ & B4 & $\begin{array}{l}\text { Araújo, F.R.; Santos, D.F.; } \\
\text { Araújo, M.A.D. }\end{array}$ & $\begin{array}{l}\text { O direito humano à alimentação adequada } \\
\text { promovido por políticas de acesso a } \\
\text { alimentos: o caso da unidade Natal-RN do } \\
\text { Projeto Café do Trabalhador }\end{array}$ \\
\hline $\begin{array}{l}\text { Saúde } \\
\text { coletiva }\end{array}$ & B4 & D’Ávila, C.A.R.; Silva, S.P. & $\begin{array}{l}\text { Segurança alimentar e desenvolvimento } \\
\text { local: uma análise dos resultados do } \\
\text { Programa de Aquisição de Alimentos (PAA) } \\
\text { em Minas Gerais }\end{array}$ \\
\hline $\begin{array}{l}\text { Saúde } \\
\text { coletiva }\end{array}$ & B4 & Melo, L.V.; Paese, C.R. & $\begin{array}{l}\text { O combate à fome no brasil: uma análise } \\
\text { da implantação do Programa Fome Zero em } \\
2003 \text { e } 2004\end{array}$ \\
\hline
\end{tabular}


Continuação

\begin{tabular}{|c|c|c|c|}
\hline $\begin{array}{l}\text { Grande } \\
\text { área }\end{array}$ & $\begin{array}{c}\text { Qualis Capes } \\
2016-2019\end{array}$ & Autores & Título \\
\hline $\begin{array}{l}\text { Saúde } \\
\text { coletiva }\end{array}$ & B4 & Costa, S.M.G. & $\begin{array}{l}\text { Agronegócio, produção de alimentos e } \\
\text { segurança alimentar na América Latina }\end{array}$ \\
\hline $\begin{array}{l}\text { Saúde } \\
\text { coletiva }\end{array}$ & C & Pereira, C.C.; Gessele, C. & $\begin{array}{l}\text { A Desnutrição Infantil como Consequência } \\
\text { dos Distúrbios Nutricionais e a Atuação do } \\
\text { Assistente Social na Garantia do Direito a } \\
\text { Alimentação Adequada }\end{array}$ \\
\hline $\begin{array}{l}\text { Saúde } \\
\text { coletiva }\end{array}$ & $\mathrm{A} 2$ & $\begin{array}{l}\text { Coutinho, M.; } \\
\text { Lucatelli, M. }\end{array}$ & $\begin{array}{l}\text { Produção científica em nutrição e percepção } \\
\text { pública da fome e alimentação no Brasil }\end{array}$ \\
\hline $\begin{array}{l}\text { Saúde } \\
\text { coletiva }\end{array}$ & B4 & Monteiro, F.; Schmidt, S. & $\begin{array}{l}\text { O Programa Bolsa Família no contexto da } \\
\text { segurança alimentar e nutricional no Brasil }\end{array}$ \\
\hline $\begin{array}{l}\text { Saúde } \\
\text { coletiva }\end{array}$ & B4 & $\begin{array}{l}\text { Marcon, M.C.; Machado, } \\
\text { P.M.O.; Moretti-Pires, R.O. }\end{array}$ & $\begin{array}{l}\text { Os discursos envolvendo o Direito humano } \\
\text { à Alimentação adequada e segurança } \\
\text { alimentar e nutricional na prática dos } \\
\text { profissionais de saúde }\end{array}$ \\
\hline $\begin{array}{l}\text { Saúde } \\
\text { coletiva }\end{array}$ & B5 & Silva, J.G.; Tavares, L. & $\begin{array}{l}\text { Segurança alimentar e a alta dos preços dos } \\
\text { alimentos: oportunidades e desafios }\end{array}$ \\
\hline $\begin{array}{l}\text { Saúde } \\
\text { coletiva }\end{array}$ & B5 & $\begin{array}{l}\text { Sampaio, M.F.A.; Kepple, } \\
\text { A.W.; Segall-Corrêa, A.M.; } \\
\text { Oliveira, J.T.A.; Panigassi, } \\
\text { G.; Maranha, L.K. et al. }\end{array}$ & $\begin{array}{l}\text { (In) Segurança Alimentar: experiência de } \\
\text { grupos focais com populações rurais do } \\
\text { Estado de São Paulo }\end{array}$ \\
\hline $\begin{array}{l}\text { Saúde } \\
\text { coletiva }\end{array}$ & B5 & $\begin{array}{l}\text { Garajau, N.I.; } \\
\text { Afonso, M.L.M. }\end{array}$ & $\begin{array}{l}\text { Articulação intersetorial como estratégia de } \\
\text { gestão na Política de Segurança Alimentar } \\
\text { e Nutricional no Brasil: análise do Programa } \\
\text { Cozinha Comunitária }\end{array}$ \\
\hline $\begin{array}{l}\text { Saúde } \\
\text { coletiva }\end{array}$ & B5 & $\begin{array}{l}\text { Menezes, R.D.; Demétrio, } \\
\text { F.; Soares, M.D.; Henrique, } \\
\text { F.C.S.; Panelli-Martins, } \\
\text { B.E.; Amparo-Santos, L. }\end{array}$ & $\begin{array}{l}\text { Efeito do Programa Bolsa Família } \\
\text { na prevalência de insegurança } \\
\text { alimentar familiar }\end{array}$ \\
\hline $\begin{array}{l}\text { Saúde } \\
\text { coletiva }\end{array}$ & B5 & Souza, L.R.; Belik, W. & $\begin{array}{l}\text { O planejamento da política de alimentação: } \\
\text { uma análise a partir dos casos do México, } \\
\text { Brasil e Peru }\end{array}$ \\
\hline $\begin{array}{l}\text { Saúde } \\
\text { coletiva }\end{array}$ & B5 & $\begin{array}{l}\text { Andrade, D.A.; Lacerdo, } \\
\text { R.S.; Silva, T.C.; Voci, S.M. }\end{array}$ & $\begin{array}{l}\text { Avaliação da situação de insegurança alimentar } \\
\text { em uma comunidade quilombola de Sergipe }\end{array}$ \\
\hline $\begin{array}{l}\text { Saúde } \\
\text { coletiva }\end{array}$ & B5 & Boog, M.C.F. & $\begin{array}{l}\text { Doação de alimentos como ação } \\
\text { emergencial de combate à fome - subsídios } \\
\text { aos COMSEAS }\end{array}$ \\
\hline $\begin{array}{l}\text { Saúde } \\
\text { coletiva }\end{array}$ & B5 & $\begin{array}{l}\text { Nobre, L.N.; Murta, } \\
\text { N.M.G.; Souza, M.M.; } \\
\text { Ferreira, N.C.; Cardoso, } \\
\text { L.M.; Hamacek, F.R. }\end{array}$ & $\begin{array}{l}\text { Segurança alimentar em uma comunidade } \\
\text { rural no Alto Vale do Jequitinhonha/MG }\end{array}$ \\
\hline $\begin{array}{l}\text { Saúde } \\
\text { coletiva }\end{array}$ & B5 & $\begin{array}{l}\text { Custódio, M.B.; Furquim, } \\
\text { N.R.; Santos, G.M.M.; } \\
\text { Cyrillo, D.C. }\end{array}$ & $\begin{array}{l}\text { Segurança alimentar e nutricional e a } \\
\text { construção de sua política: uma visão } \\
\text { histórica }\end{array}$ \\
\hline
\end{tabular}


Continuação

\begin{tabular}{|l|c|l|l|}
\hline $\begin{array}{l}\text { Grande } \\
\text { área }\end{array}$ & $\begin{array}{c}\text { Qualis Capes } \\
\mathbf{2 0 1 6 - 2 0 1 9}\end{array}$ & \multicolumn{1}{|c|}{ Autores } & \multicolumn{1}{c|}{ Título } \\
\hline $\begin{array}{l}\text { Saúde } \\
\text { coletiva }\end{array}$ & B5 & Belik, W. & $\begin{array}{l}\text { A política brasileira de segurança alimentar } \\
\text { e nutricional: concepção e resultados }\end{array}$ \\
\hline $\begin{array}{l}\text { Saúde } \\
\text { coletiva }\end{array}$ & B5 & $\begin{array}{l}\text { Machado, M.; Rocha, } \\
\text { D.F.; Campos, M.M. }\end{array}$ & $\begin{array}{l}\text { Dos movimentos sociais à implementação } \\
\text { do Programa Fome Zero (1993 - 2013): a } \\
\text { trajetória da cidadania alimentar no Brasil } \\
\text { (20 anos da ação da cidadania e 10 anos do } \\
\text { Programa Fome Zero) }\end{array}$ \\
\hline $\begin{array}{l}\text { Saúde } \\
\text { coletiva }\end{array}$ & B5 & Figueiredo, N. & $\begin{array}{l}\text { A experiência brasileira em segurança } \\
\text { alimentar e o trabalho do Centro de } \\
\text { Excelência contra a fome do Programa } \\
\text { Mundial de Alimentos }\end{array}$ \\
\hline
\end{tabular}

Fonte: pesquisa direta

Foram selecionados apenas manuscritos científicos que estavam disponíveis para acesso on-line e publicados no idioma português, totalizando 94 publicações. No conteúdo de cada manuscrito, foram buscados os seguintes termos: "efetiv ${ }^{\star ” ;}$ "direito humano à alimentação adequada"; "direito à alimentação"; "DHAA"; "fome"; "alimentação"; "aliment*”.

Após esses procedimentos, extraíram-se os excertos que continham os termos acima descritos. Para fins deste estudo, já que o foco se trata da efetividade do DHAA, trabalhou-se apenas com os excertos que continham o termo derivado "efetiv", que passaram por análise de conteúdo lexical, processados pelo software Iramuteq. Focou-se apenas em três tipos de análise empreendida pelo software nos textos: a análise estatística descritiva do número de repetições do termo por área, a análise fatorial de correspondência (AFC) e análise de similitude.

A análise estatística serve para executar estatísticas simples sobre o corpus textual, por meio dos seguintes procedimentos: identificação e reformatação das unidades de texto; e identificação da quantidade de palavras, assim como sua frequência média. A análise fatorial de correspondência (AFC) corresponde ao cruzamento entre o vocabulário (considerando a frequência de incidência de palavras) e as classes, gerando uma representação gráfica em plano cartesiano na qual são vistas as oposições entre classes ou formas. Já a análise de similitude mostra um grafo que representa a ligação entre palavras do corpus textual. A partir desta análise da concorrência entre as palavras, é possível inferir a estrutura de construção do texto e os temas de relativa importância. Ao final, é possível perceber melhor a relação das áreas do direito e da saúde coletiva com a produção sobre a efetividade jurídica do DHAA enquanto direito social e humano. 


\section{Resultados e discussão}

Após a análise de conteúdo, percebeu-se, pela estatística textual (Tabela 1), que o número de repetições do termo "efetiv ${ }^{\star}$ " nos manuscritos selecionados nas áreas de direito e saúde coletiva é bem desproporcional, o que demonstra a frequência da ideia de efetividade (e termos com o mesmo radical) mais presente nas publicações da área da saúde coletiva do que no direito. Isso chama atenção, pois. como apontam Burity et al. ${ }^{21}$, o DHAA está previsto em diversos tratados e documentos internacionais e nas legislações vigentes em nosso país. É garantido internacionalmente desde a Declaração Universal dos Direitos Humanos da Organização das Nações Unidas (ONU, 1948) 22 e o Pacto Internacional dos Direitos Econômicos, Sociais e Culturais (Pidesc, 1966), ratificado no Brasil em $1992^{23}$, e se realiza quando todas as pessoas têm acesso garantido e ininterrupto à alimentação adequada e saudável por meios próprios e sustentáveis. Nesse sentido, para Soares ${ }^{24}$, o direito à alimentação pode ser visto como um direito social e político. Contudo, ainda não adentrou a cena da pesquisa do direito como a devida força.

Burity et al. também afirmam que, embora o artigo 11 do Pidesc reconheça "o direito de todos a um padrão de vida adequado [...] inclusive alimentação adequada" e "o direito fundamental de todos de estar livre da fome [...]"25, o DHAA e sua devida efetividade não são pautados na área do direito, mesmo que suas duas dimensões sejam reconhecidas do ponto de vista jurídico: o direito de estar livre da fome e o direito à alimentação adequada, cuja realização é essencial para a fruição de todos os direitos humanos ${ }^{26,27,28}$. Assim, pode-se dizer que o DHAA e o direito de estar livre da fome ainda estão distantes da realidade de muitas pessoas em todo o mundo ${ }^{29}$.

${ }^{21}$ BURITY, Valéria et al. Direito humano à alimentação adequada no contexto da segurança alimentar e nutricional. Brasília-DF: ABRANDH, 2010. p. 15. conferir a paginação. 15p. ou p.15? 0 documento tem 204p.

${ }^{22}$ NAÇÕES UNIDAS. Declaração Universal dos Direitos Humanos. Adotada e proclamada pela Assembleia Geral das Nações Unidas (resolução 217 A III) em 10 de dezembro 1948. UNICEF. Disponível em: https:// www.unicef.org/brazil/declaracao-universal-dos-direitos-humanos. Acesso em: 21 abr. 2021.

${ }^{23}$ BRASIL. Decreto n. 591, de 6 de julho de 1992. Atos Internacionais. Pacto Internacional sobre Direitos Econômicos, Sociais e Culturais. Promulgação. Disponível em: http://www.planalto.gov.br/ccivil_03/ decreto/1990-1994/d0591.htm. Acesso em: 21 abr. 2021.

${ }^{24}$ SOARES, Sônia. Análise do direito humano à alimentação adequada: um direito social e político, cit., p. 36-54.

${ }^{25}$ BURITY, Valéria et al. op. cit.

${ }^{26}$ BURITY, Valéria et al. op. cit.

${ }^{27}$ MACHADO, Renato Luiz Abreu. Direito humano à alimentação adequada. Publicado em: 29 maio 2017. Disponivel em: http://www4.planalto.gov.br/consea/acesso-a-informacao/institucional/conceitos/direitohumano-a-alimentacao-adequada. Acesso em: 22 ago. 2018.

${ }^{28}$ SOARES, Sônia. Análise do direito humano à alimentação adequada: um direito social e político, cit., p. 36-54.

${ }^{29}$ GUERRA, Lúcia Dias da Silva. Alimentação: um direito humano em disputa - focos temáticos para compreensão e atuação em segurança alimentar e nutricional. Ciênc. saúde coletiva, v. 24, n. 9, p. 33693394, set. 2019. Disponível em: https://www.scielo.br/pdf/csc/v24n9/1413-8123-csc-24-09-3369.pdf. https://doi.org/10.1590/1413-81232018249.20302017. 
Tabela 1. Número de repetições do termo "efetiv*" nos artigos selecionados nas áreas do direito e saúde coletiva. Abril. 2018.

\begin{tabular}{lcc}
\hline \multirow{2}{*}{ Área } & \multicolumn{2}{c}{ Efetiv* } \\
\cline { 2 - 3 } & Número de repetições do termo & $\%$ \\
\hline Direito & 7 & 2,7 \\
Saúde coletiva & 254 & 97,3 \\
Total & 261 & 100,0 \\
\hline
\end{tabular}

Fonte: pesquisa direta

Pode-se afirmar, ainda, que o estudo da efetividade do DHAA não apresenta a devida correspondência ao se analisarem os excertos na área do direito em comparação com a área da saúde coletiva. Esta última, segundo a análise fatorial de correspondência (Quadro 2), parece estar mais afeita ao estudo da efetividade do DHAA em sua agenda de pesquisa. Não obstante, os resultados positivos do Quadro 2 apontam que as formas nominais derivadas do termo "efetiv ${ }^{\star}$ " estão correlacionadas de forma positiva com a área da saúde coletiva.

Quadro 2. Número de repetições das formas nominais derivadas do termo "efetiv*" e a análise fatorial de correspondência (AFC) entre as formas nominais nos excertos dos artigos selecionados nas áreas de direito e saúde coletiva. Abril. 2018.

\begin{tabular}{|l|c|c|c|}
\hline \multirow{2}{*}{ Forma nominal } & \multicolumn{3}{|c|}{ Termo principal } \\
\cline { 2 - 4 } & $\mathbf{N}$ & Efetiv* no direito & Efetiv* na saúde coletiva \\
\hline Efetiv(o) & 97 & $-0,457$ & 0,457 \\
\hline Efetiv(ação) & 56 & $-0,571$ & 0,571 \\
\hline Efetiv(idade) & 38 & $-0,319$ & 0,319 \\
\hline Efetiv(ar) & 31 & $-0,232$ & 0,232 \\
\hline Efetiv(amente) & 30 & $-0,220$ & 0,220 \\
\hline
\end{tabular}

Fonte: pesquisa direta

Entretanto, a preocupação da produção científica da área da saúde coletiva não tem se restringido apenas ao texto de lei ou ao ordenamento jurídico pátrio, como o direito à alimentação assim tipificado no artigo $6^{\circ} \mathrm{da} \mathrm{CF} / 88$ juntamente com os demais direitos sociais fundamentais (educação, saúde, trabalho, moradia, lazer, segurança, previdência social, proteção à maternidade e à infância e assistência aos desamparados). Indo além, a alimentação, incluída nesse rol como um direito social pela Emenda Constitucional n. 64/2010, é trabalhada, em sua expressão concreta, como política pública desde 1999, quando se estabeleceram as bases 
e diretrizes da Política Nacional de Alimentação e Nutrição (PNAN) ${ }^{30}$ - a primeira política setorial na defesa do DHAA e que, posteriormente, tornou-se central na agenda governamental com a criação da Lei Orgânica de Segurança Alimentar e Nutricional (LOSAN), em 2016.

Barros e Tartaglia ${ }^{31}$ entendem que tal política não tem sido eficiente no combate à desnutrição. Para os autores, em que pese a preocupação com a efetividade do DHAA por meio das políticas públicas, há limites no que tange a uma única política em que haja sinergia necessária das demais em uma lógica de proteção.

Assim, considera-se importante que, a partir de 2001, surjam os primeiros programas de transferência de renda para ajudar a concretizar o DHAA, ainda que de forma inicial. Na visão de Barros e Tartaglia ${ }^{32}$, mesmo com esse avanço, os valores repassados ainda eram insuficientes para se alcançar a qualidade de vida, e muitas famílias ainda se encontravam em situação de miséria e pobreza. Tais programas, na visão dos autores, só protelavam a situação.

Contudo, Martins et al..$^{33}$ buscaram relacionar a influência dos Programas de Transferência Condicionada de Renda (PTCR) na alimentação das famílias beneficiadas no Brasil. Na revisão sistemática que esses autores empreenderam, delimitaram três desfechos nutricionais: consumo alimentar, estado nutricional e segurança alimentar.

Estudos realizados em diferentes regiões do mundo mostram que as pessoas mais vulneráveis à violação do direito humano à alimentação são as que vivem em situação de insegurança alimentar grave, têm origem latina ${ }^{34}$, apresentam cor da pele preta ou parda ${ }^{35}$, possuem baixa escolaridade ${ }^{36}$ e baixa renda ${ }^{37}$ e têm alimentação

\footnotetext{
${ }^{30}$ LISBOA, Renata Cardoso. Direito humano à alimentação adequada. Revista Eletrônica de Direito, out. 2013. Disponível em: http://npa.newtonpaiva.br/direito/?p=1464. Acesso em: 24 ago. 2018.

${ }^{31}$ BARROS, Maria Sylvia Carvalho; TARTAGLIA, José Carlos. A política de alimentação e nutrição no Brasil: breve histórico, avaliação e perspectivas. Alim. Nutr., Araraquara, v.14, n.1, p. 109-121, 2003. Disponível em: http://serv-bib.fcfar.unesp.br/seer/index.php/alimentos/article/viewFile/847/726.

${ }^{32}$ Id. Ibid.

${ }^{33}$ MARTINS, Ana Paula Bortoletto etal. Transferência de renda no Brasil e desfechos nutricionais: revisão sistemática. Rev. Saúde Pública, São Paulo, v. 47, n. 6, p. 1159-1171, dez. 2013. Disponível em: https://www.scielo.br/pdf/ rsp/v47n6/0034-8910-rsp-47-06-01159.pdf. https://doi.org/10.1590/S0034-8910.2013047004557.

${ }^{34}$ KERSEY, Margaret; GEPPERT, Joni; CUTTS, Diana B. Hunger in young children of Mexican immigrant families. Public Health Nutr, v. 10, n. 4, p. 390-395, 2007. Disponivel em: https://www.cambridge.org/core/services/aopcambridge-core/content/view/4F3B036BEBAA389935D8F4A34270381A/S1368980007334071a.pdf/ hunger-in-young-children-of-mexican-immigrant-families.pdf. https://doi.org/10.1017/S1368980007334071.

${ }^{35}$ KAISER, Lucia L.; MELGAR-QUIÑONEZ, Hugo R.; TOWNSEND, Marilyn S.; NICHOLSON, Yvonne; FUJ, Mary Lavender; MARTIN, Anna C.; LAMP, Cathi L. Food insecurity and food supplies in Latino households with young children. J Nutr Educ Behav., v. 35, n. 3, p. 148-153, May/June 2003. https://doi.org/10.1016/ S1499-4046(06)60199-1.

${ }^{36}$ CARTER, Kristie N; LANUMATA, Tolotea; KRUSE, Kerri; GORTON, Delvina. What are the determinants of food insecurity in New Zealand and does this differ for males and females? Aust NZ J Public Health, v. 34, n.6, p. 602-608, Dec. 2010. http://dx.doi.org/10.1111/j.1753-6405.2010.00615.x.

${ }^{37}$ CUTLER-TRIGGS, Cynthia; FRYER, George E; MIYOSHI, Thomas J; WEITZMAN, M. Increased rates and severity of child and adult food insecurity in households with adult smokers. Arch Pediatr Adolesc Med., v. 162, n. 11, p. 1056-1062, Nov. 2008. http://dx.doi.org/10.1001/archpediatrics.2008.2.
} 
inadequada ${ }^{38,39}$. Além disso, a expressão da insegurança alimentar e nutricional perpassa as desigualdades sociais, étnico-raciais e de gênero, a falta de acesso e a disponibilidade aos alimentos saudáveis, o consumo de alimentos de qualidade nutricional inadequada, as doenças e os agravos que se reverberam no comprometimento das condições de saúde ${ }^{40,41}$.

Por isso que, ao estudar as formas nominais dos termos subsidiários (ou seja, aqueles com que a ideia de efetividade do DHAA se relaciona diretamente), as formas que tratam de uma ação direta do direito (sua realização no cotidiano) apresentam também uma configuração fatorial de correspondência mais identificada com a saúde coletiva do que com a produção científica do direito. Isso remete a pensar o quanto a produção de conhecimento no direito sobre a própria efetividade deste não dialoga com a vida concreta do "alimentar-se", da "fome", do "acesso" ao "alimento". A única forma, que, curiosamente é positiva para efetividade no conteúdo produzido pelo direito é a ideia de "ação" (Quadro 3).

Quadro 3. Número de repetições das formas nominais subsidiárias ao termo "efetiv*" e a análise fatorial de correspondência (AFC) entre as formas nominais nos excertos dos artigos selecionados nas áreas de direito e saúde coletiva. Abril. 2018.

\begin{tabular}{|l|c|c|c|}
\hline \multirow{2}{*}{ Forma nominal } & \multicolumn{3}{|c|}{ Termos subsidiários } \\
\cline { 2 - 4 } & $\mathbf{N}$ & Direito & Saúde coletiva \\
\hline Alimentar & 67 & $-1,369$ & 1,369 \\
\hline Ação & 64 & 0,250 & $-0,250$ \\
\hline Fome & 27 & $-0,186$ & 0,186 \\
\hline Acesso & 27 & $-0,547$ & 0,547 \\
\hline Alimento & 26 & $-0,526$ & 0,526 \\
\hline
\end{tabular}

Fonte: pesquisa direta

\footnotetext{
${ }^{38}$ ROSAS, Lisa G; HARLEY, Kim; FERNALD, Lia CH; GUENDELMAN, Sylvia; MEJIA, Fabiola; NEUFELD, Lynnette M.; ESKENAZI, Brenda. Dietary associations of household food insecurity among children of Mexican descent: results of a binational study. J Am Diet Assoc., v. 109, n. 12, p. 2001-2009, Dec. 2009. https:// doi.org/10.1016/j.jada.2009.09.004.

${ }^{39}$ SHOAE, Nahid Zerafati; OMIDVAR, Nasrin; GHAZI-TABATABAIE, Mahmood; RAD, Anahita Houshiar; FALLAH, Hajieh; MEHRABI, Yadollah. Is the adapted Radimer/Cornell questionnaire valid to measure food insecurity of urban households in Tehran, Iran? Public Health Nutr, v. 10, n. 8, p. 855-861, Aug. 2007. https://doi. org/10.1017/S1368980007441465.

${ }^{40}$ ROCHA, Cecília; BURLANDY, Luciene; MAGALHÃES, Rosana. Segurança alimentar e nutricional: perspectivas, aprendizados e desafios para as políticas públicas. Rio de Janeiro: Fiocruz, 2013.

${ }^{41}$ MINISTÉRIO DO DESENVOLVIMENTO SOCIAL E COMBATE À FOME. Câmara Interministerial de Segurança Alimentar e Nutricional - CAISAN. Plano Nacional de Segurança Alimentar e Nutricional: 2012/2015. Brasília-DF: CAISAN, 2011. Disponível em: https://www.mds.gov.br/webarquivos/publicacao/seguranca_ alimentar/Plano_Caisan.pdf.
} 
Ao se identificar o conteúdo relacionado à ideia de ação nos excertos retirados dos manuscritos na área do direito, percebe-se que se trata a ação em âmbito governamental (do Estado, titular de obrigações), e não a ação relativa ao acesso ao alimento ou ao enfrentamento concreto da fome (vinculado às pessoas, titulares de direito) ${ }^{42}$.

Uma ação enquanto política pública que vise a garantir o direito à alimentação à população deve englobar diferentes segmentos da sociedade e da cadeia produtiva, e não apenas focar o aspecto jurídico-institucional da ação governamental, conforme mostram os movimentos constitutivos da luta pela segurança alimentar e nutricional no Brasil. Para a grande maioria da população do planeta, o ato da alimentação depende de mecanismos complexos de decisão dos produtores capitalistas, do papel de intervenção do Estado, dos subsídios à agricultura, do grau de concentração da terra, do capital investido na indústria alimentar etc. A distribuição de alimentos só se justificaria em situações emergenciais, como catástrofes ambientais. Novas formas de garantir a todos o acesso aos alimentos básicos necessários e suficientes devem ser buscadas ${ }^{43}$. O artigo $3^{\circ}$, da Lei n. 11.436/2006 define que o acesso aos alimentos deve ser

regular e permanente a alimentos de qualidade, em quantidade suficiente, sem comprometer o acesso a outras necessidades essenciais, tendo como base práticas alimentares promotoras da saúde que respeitem a diversidade cultural e que sejam ambiental, cultural, econômica e socialmente sustentáveis.

Ao se pensar historicamente, entre o fim do século XIX e início do XX, o enfrentamento da fome por meio de ações de combate à pobreza padecia de um preconceito. A pobreza era vista como um comportamento vicioso, um desvio moral, e o Estado era ausente. Portanto, a pobreza era levada com desconfiança pela lógica do direito. Depois, foi vista como ameaça à ordem social que deveria ser controlada pelo poder público, e a fome era central neste controle. As principais ações do Estado, naquele período, concentravam-se no controle da pobreza por meio de ações higienistas e moralizadoras da pobreza e da miséria ${ }^{44,45}$.

Quando se verifica a similitude dentre as formas nominais da efetividade do DHAA nas duas áreas de conhecimento, percebe-se a construção de racionalidade

\footnotetext{
${ }^{42}$ ZIMMERMANN, Clóvis Roberto. Os programas sociais sob a ótica dos direitos humanos: o caso do Bolsa Família do governo Lula no Brasil. Sur, Rev. int. direitos human., São Paulo, v. 3, n. 4, p. 144-159, jun. 2006. Disponivel em: https://www.scielo.br/pdf/sur/v3n4/08.pdf.

${ }^{43}$ BARROS, Maria Sylvia Carvalho; TARTAGLIA, José Carlos. op. cit., p. 109-121.

${ }^{44}$ ANJOS, João Guilherme Sampaio dos. O papel da assistência social na efetivação dos direitos sociais. Revista de Direito Sociais e Políticas Públicas, Brasília, v. 2, n. 1, p. 85-104, jan./jun. 2016. Disponível em: http://dx.doi.org/10.26668/IndexLawJournals/2525-9881/2016.v2i1.546.

${ }^{45}$ COSTA, Luiza Elena da; MESQUITA, Vânia Maria de; CAMPOS, Ana Paula. Moradores de rua, quem são eles? um estudo sobre a população de rua atendida pela Casa da Sopa “Capitão Vendramini" de Três Corações. Revista da Universidade Vale do Rio Verde, 13, n. 2, p. 285-297, 2015. Disponível em: http://periodicos.unincor.br/ index.php/revistaunincor/article/view/2281/pdf_377. http://dx.doi.org/10.5892/ruvrd.v13i1.2281.
} 
de pesquisa sobre o direito à alimentação e sua efetividade e, assim, como essas áreas delimitam suas narrativas sobre o problema (Figura 1).

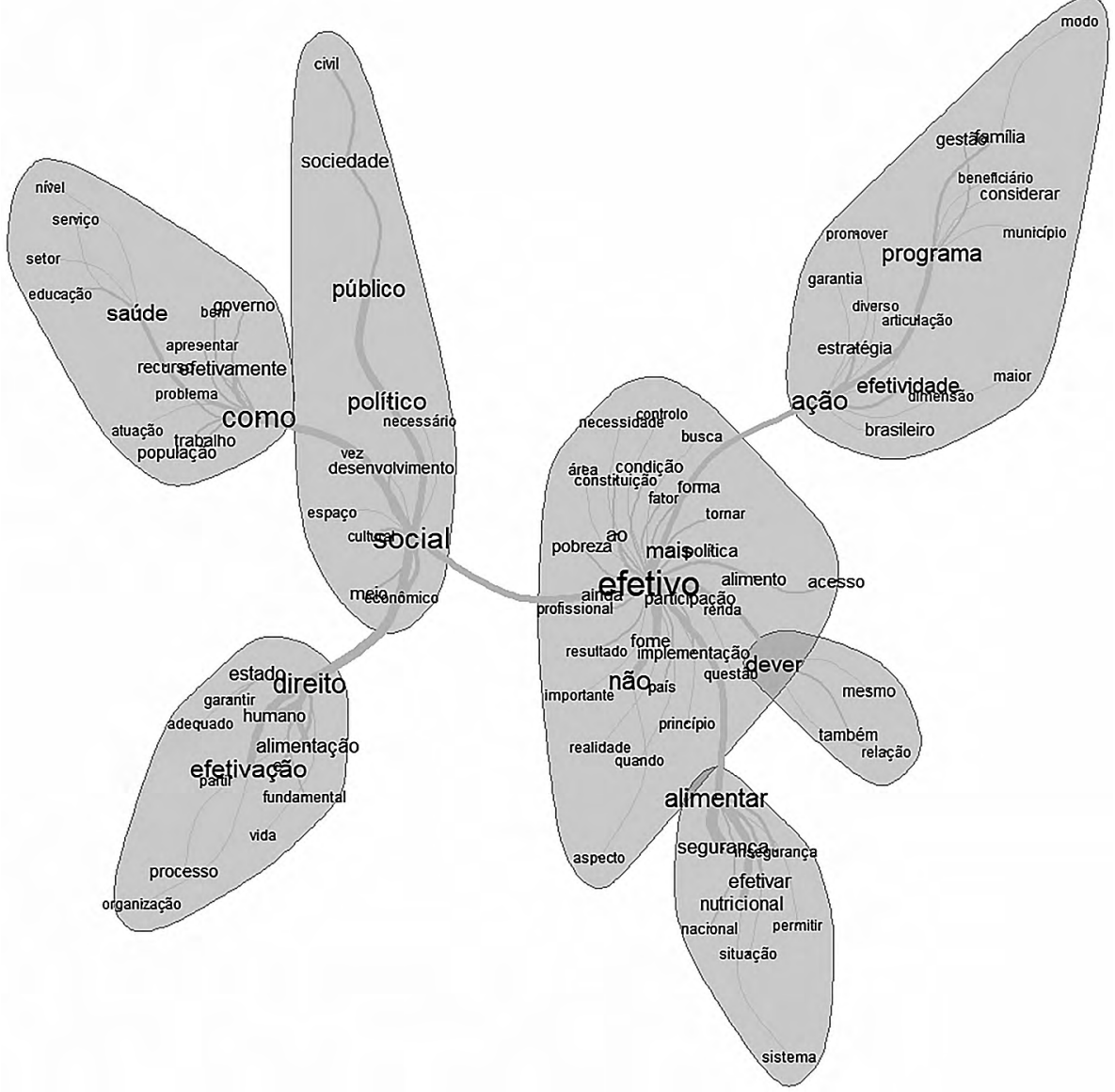

Fonte: pesquisa direta

Figura 1. Análise de similitude entre as formas nominais dos excertos retirados dos manuscritos do direito e da saúde coletiva sobre a efetividade do direito humano à alimentação adequada. Abril. 2018.

Na Figura 1, ao termo "efetivo", encontra-se no centro por deter a centralidade do debate empreendido neste estudo acerca do conteúdo da produção científica estudada. As similitudes se derivam para quatro polos. O primeiro e mais importante, relacionado com o "social", compreende o DHAA como uma decisão política 
para o desenvolvimento econômico, necessário para a sociedade civil. Deste polo, se derivam duas narrativas: uma que foca o "como" fazer, ou seja, como implementar essa ideia, traduzindo-a no trabalho com a população e na educação como setor/ serviço a ser utilizado como recurso governamental (a exemplo do setor/serviço saúde); e a que considera que o direito e sua efetivação pelo Estado dependem do processo de organizar esse direito humano como direito à vida, ligado à noção de dignidade humana ratificada extensamente nas normas jurídicas sobre o DHAA.

Os outros três polos, minoritários, associam "efetivo" a: "ação", "alimentar" e "dever". Sobre à relação entre "efetivo" e "ação", a narrativa traduz-se pela efetividade dos programas em garantir as articulações necessárias entre as dimensões jurídica e fatídica (garantia programática); este parece ser o grande entrave do debate. Ao se relacionar "efetivo" com "alimentar", percebe-se que as pesquisas tentam descrever maneiras de se efetivar a segurança alimentar e nutricional. Por último, no que tange a "dever", a narrativa parece ser a mais débil nos estudos de maneira geral e se traduz na compreensão de que "efetivo" relacionado ao DHAA também é um dever das pessoas.

Este debate coloca novamente em pauta a discussão do termo, ainda que polissêmico, "efetividade jurídica" e de seus pressupostos. Quando se trata da efetividade dos direitos sociais, deve-se sempre ter em mente que o Judiciário é apenas uma das frentes dessa árdua batalha. Acreditar que a busca pela máxima efetividade dos direitos sociais prestacionais pode ser alcançada apenas no âmbito do Judiciário é no mínimo ingênuo, pois a luta central para a efetivação desses direitos ocorre no terreno do processo democrático por meio do exercício da democracia representativa, bem como pelo intenso desenvolvimento de mecanismos de democracia participativa ${ }^{46}$. Assim, a formação, o reconhecimento e a positivação dos direitos passam a figurar como uma mera exterioridade, totalmente alheia ao comprometimento real da constituição com a particularidade dos povos, denunciando, cada vez mais, as ambivalências do terreno dos direitos fundamentais quando considerados do ponto de vista teórico ou da justificação, ao invés de sua existência material ou da efetividade jurídica ${ }^{47}$.

O tema da efetividade, ao ser exposto, diz respeito ao problema da efetividade das normas constitucionais. Efetividade, em sentido amplo, significa capacidade que uma norma jurídica tem para produzir seus efeitos. A efetividade pode ser classificada em efetividade jurídica e efetividade social. A efetividade jurídica ocorre quando a norma jurídica tem nos limites objetivos todos os seus elementos:

${ }^{46}$ SALES, Bruno Olivo de. A efetividade do direito à saúde no sistema constitucional brasileiro. 2005. $75 f$. (Graduação em Direito) - Universidade Federal do Paraná, Curitiba, 2005.

${ }^{47}$ ENGELMANN, João Gilberto. Direitos fundamentais e efetividade: o desafio da inclusão social numa economia não sustentável. Revista Direito em Debate, v. 23, n. 42, p. 68-82, 2014. Disponível em: https://www.revistas.unijui.edu.br/index.php/revistadireitoemdebate/article/view/3113/3507. https:// doi.org/10.21527/2176-6622.2014.42.68-82. 
hipótese, disposição e sanção, podendo produzir efeitos desde logo no mundo dos fatos, seja quando é respeitada, seja quando é violada, ensejando a aplicação de uma sanção. Mesmo que se admita que a efetividade das normas se consolide em diferentes planos (sintático, semântico e pragmático), trata-se aqui da ação prática ou pragmática em questão nos estudos sob análise ${ }^{48}$.

Por isso, não há como desvincular o debate sobre a efetividade jurídica do DHAA sem tematizar, compulsoriamente, o debate e o enfrentamento da pobreza e da fome. A pobreza tem origem complexa e multidimensional ${ }^{49}$. No Brasil, a conceituação de pobreza pode abranger diversos aspectos. Para a Organização das Nações Unidas para a Alimentação e Agricultura (FAO), pobreza é não ter dinheiro suficiente para comprar alimentos a fim de obter 1.700 quilocalorias ao dia. Já o Ministério do Desenvolvimento Social e Agrário considera pobre aquele que tem renda familiar de até 140 reais por mês, classificando em extrema pobreza quem tem renda familiar de até 70 reais por mês. O Instituto Brasileiro de Geografia e Estatística (IBGE) adotou sete critérios para determinar extrema pobreza, incluindo aspectos relacionados a condição de moradia, saneamento básico, acesso a água tratada e outros. Pesquisas demonstraram que, no Brasil, a maioria em extrema pobreza são mulheres, negros e pardos, crianças e pessoas em situação de rua ${ }^{50}$.

Mesmo anteriormente à publicação das leis brasileiras referentes aos alimentos, os problemas de alimentação e nutrição eram discutidos no âmbito de congressos e reuniões de comissões governamentais, resultando, na maioria das vezes, apenas na publicação de material didático e informativo. Atualmente, a alimentação está ratificada como um direito na $\mathrm{CF} / 88$, ou seja, possui força normativa e vários programas já foram instituídos no país por meio da política pública de segurança alimentar e nutricional. Com as mudanças políticas, também mudaram e se reestruturaram os programas de alimentação e nutrição, bem como a concepção do direito à alimentação e sua forma de efetivação.

Na década de 1930, os primeiros programas de alimentação de nutrição eram focados em distribuir alimentos (uma forma de utilizar os excedentes da produção agrícola mundial e nacional). Os primeiros estudos e debates sobre problemas nutricionais começam a surgir e um agente importante neste cenário foi Josué de Castro. O objetivo dos estudiosos era promover padrões adequados de alimentação para a população e propor normas de política nacional de alimentação. A evolução

\footnotetext{
${ }^{48}$ SANTOS, Marcos André Couto. A efetividade das normas constitucionais (as normas programáticas e a crise constitucional). Revista de Informação Legislativa. Brasília-DF, ano 37, n. 147, p. 5-14, jul./set. 2000. Disponível em: https://www2.senado.leg.br/bdsf/bitstream/handle/id/602/r147-01.PDF?sequence=4\&isAllowed=y.

${ }^{49}$ MARTINS, Ana Paula Bortoletto et al. op. cit., p.1159-1171.

${ }^{50}$ INSTITUTO BRASILEIRO DE GEOGRAFIA E ESTATÍSTICA - IBGE. Síntese de indicadores sociais: uma análise das condições de vida da população brasileira: 2018. Coordenação de População e Indicadores Sociais. Rio de Janeiro: IBGE, 2018. 151 p. (Estudos e pesquisas. Informação demográfica e socioeconômica; n. 39). Disponível em: https://biblioteca.ibge.gov.br/visualizacao/livros/liv101629.pdf.
} 
histórica mostra que surgem várias instituições nesse período com esse objetivo. Na década de 1950, surgiram os primeiros programas de distribuição de alimentos a segmentos específicos da população, além do primeiro programa de merenda escolar, o mais antigo dos programas ainda existentes, atualmente transformado em Programa Nacional de Alimentação Escolar (PNAE) e o Programa de Alimentação do Trabalhador (PAT) $)^{51,52}$.

Hoje, no entanto, já se sabe que a efetivação do DHAA depende necessariamente da efetivação de diversas outras políticas - por isso, a Política Nacional de Segurança Alimentar e Nutricional propõe-se a ser intersetorial -, tais como os programas de transferência de renda, nos quais os dados sobre consumo de alimentos indicam de que maneira a renda familiar é revertida em alimentação e como as famílias se comportam com o recebimento da transferência de renda, demonstrando como o direito e a efetividade das normas jurídicas ainda precisam avançar muito na garantia da expressão concreta do direito.

Alguns estudos mostram que os programas de transferência de renda têm colaborado para a redução da desigualdade e da pobreza extrema em países da América Latina, como Brasil, México, Equador, Colômbia e Chile ${ }^{53,54}$. Esses programas têm dado uma contribuição importante para o cenário de SAN quando combinado com outros tipos de intervenção, como a promoção da alimentação saudável em diversos ambientes, a regulamentação da propaganda de alimentos, $o$ monitoramento da qualidade da alimentação escolar, os programas de infraestrutura e outras ações que impactam o sistema produtivo e alimentar ${ }^{55}$.

É importante destacar que, em casos de violação do direito à alimentação, o cidadão tem direito de solicitar medidas de reparação. Ele pode, junto às frentes parlamentares estaduais de SAN e ao Ministério Público, solicitar abertura de inquérito civil como instrumento de exigibilidade de direito extrajudicial ou de uma ação civil pública para proteção judicial de direitos coletivos. Outro espaço de manifestação da sociedade para exigibilidade de direitos são as audiências

\footnotetext{
${ }^{51}$ BOSI, Maria Lúcia Magalhães. A face oculta da nutrição: ciência e ideologia. Rio de Janeiro: Espaço e Tempo; Ed. UFRJ, 198.

${ }^{52}$ BURLANDY, Luciene. A atuação da sociedade civil na construção do campo da Alimentação e Nutrição no Brasil: elementos para reflexão. Ciênc. saúde coletiva, Rio de Janeiro, v. 16, n. 1, p. 63-72, jan. 2011. Disponível em: http://www.scielo.br/pdf/csc/v16n1/v16n1a10.pdf. Acesso em: 13 ago. 2019. http:// dx.doi.org/10.1590/S1413-81232011000100010.

${ }^{53}$ COTTA, Rosângela Minardi Mitre; MACHADO, Juliana Costa. Programa Bolsa Família e segurança alimentar e nutricional no Brasil: revisão crítica da literatura. Rev. Panam Salud Publica, v. 33, n. 1, p. 54-60, 2013. Disponível em: https://www.scielosp.org/pdf/rpsp/2013.v33n1/54-60.

${ }^{54}$ SOARES, Fábio Veras; PEREZ RIBAS, Rafael; OSÓRIO, Rafael Guerreiro. Evaluating the impact of Brazil's Bolsa Família: cash transfer programs in comparative perspective. Latin American Research Review, v. 45, n. 2, p. 173-190, 2010. https://doi.org/10.1353/lar.2010.0017.

${ }^{55}$ OSÓRIO, Mônica Maria; RIBEIRO, Marisilda de Almeida; COSTA, Emilia Chagas; SILVA, Silvia Patrícia de Oliveira; FERNANDES, Carolina Estevam. Disponibilidade familiar de alimentos na Zona da Mata e SemiÁrido do Nordeste do Brasil. Rev. Nutr., Campinas. v. 22, n. 3, p. 319-329, jun. 2009. Disponível em: https:// www.scielo.br/pdf/rn/v22n3/v22n3a02.pdf. https://doi.org/10.1590/S1415-52732009000300002.
} 
públicas no Poder Legislativo, inclusive para fazer com que agentes públicos adequem suas ações às normas que preveem o DHAA, utilizando os Termos de Ajustamento de Conduta ${ }^{56}$.

No entanto, de modo geral, essa lógica de participação social para a garantia de direitos como o DHAA ainda permanece distante da população. Com isso, persiste o inquietante desafio de fortalecer os espaços de participação popular enquanto instâncias democráticas capazes de dialogar sobre as necessidades da população na implementação das políticas públicas, além de torná-los convidativos para o engajamento e o protagonismo de redes de associações, movimentos sociais e universidades ${ }^{57}$.

Considerando alguns avanços e sem deixar de lado o construto histórico da complexa realidade alimentar brasileira e suas profundas marcas de desigualdade, o grande desafio que se coloca é o que e como fazer para que tais políticas públicas de fato deem conta das questões fundamentais da alimentação e nutrição, de forma associada à promoção de processos que enfrentem situações de insegurança alimentar e nutricional, de modo a contribuir principalmente para mudanças estruturais na sociedade. O cenário brasileiro atual aponta para o escamoteamento das políticas públicas sociais e anuncia processos de instabilidade na garantia dos direitos sociais. Assim, ecoa a contínua necessidade da discussão sobre o papel do Estado e o desmonte dos espaços institucionalizados e não institucionalizados de participação da sociedade, principalmente no que tange ao atual modelo adotado para a sustentação das políticas públicas sociais ${ }^{58}$.

Importante lembrar que o DHAA e os demais direitos sociais estão em disputa a todo o tempo, no plano teórico-conceitual, na construção ou permanência de princípios ou também no âmbito da formulação e implementação das políticas públicas, na medida em que a organização social e política e as relações de poder se rearranjam em uma sociedade, constituindo-se num campo em permanente construção ${ }^{59}$.

\section{Conclusão}

Ante o exposto, é possível afirmar que a efetividade do direito humano à alimentação adequada apresenta uma diferença significativa como objeto de estudo na área do direito e na área da saúde coletiva. A área do direito, em que pese a

\footnotetext{
${ }^{56}$ GUERRA, Lúcia Dias da Silva. Direito humano à alimentação adequada e atuação profissional em saúde pública, cit.

${ }^{57}$ BURLANDY, Luciene. op. cit., p. 63-72.

${ }^{58}$ GUERRA, Lúcia Dias da Silva. Direito humano à alimentação adequada e atuação profissional em saúde pública, cit.

${ }^{59}$ GUERRA, Lúcia Dias da Silva. Alimentação: um direito humano em disputa - focos temáticos para compreensão e atuação em segurança alimentar e nutricional, cit., p. 3369-3394.
} 
preocupação com "efetivar o direito", ainda não avançou na efetividade como prática concreta, ou seja, pragmática em si. Poucos são os manuscritos na área do direito sobre esse tema, e os que existem compreendem a efetividade jurídica do DHAA como ações em âmbito governamental, e não necessariamente relativas ao acesso ao alimento ou ao enfrentamento concreto da fome.

Em contrapartida, os estudos na área da saúde coletiva pautam a efetividade do DHAA de forma pragmática e expressam a diversidade de políticas e enfrentamentos que deve estar em pauta quando se considera do DHAA como objeto de investigação. Ainda assim, os estudos nessa área focam a efetividade desse direito para o desenvolvimento econômico, necessário para a sociedade civil. Ou seja, mais "capitalismo" para efetivação do direito via Estado apoiando-se na educação como setor/serviço a ser utilizado como recurso governamental.

Portanto, é pertinente ressaltar que este estudo avança na discussão por demonstrar sistematicamente que essas formas de apreensão do DHAA de fato estão de acordo com o que se pensava sobre elas. Assim, mesmo sob a relevante proposta das áreas do direito e da saúde coletiva de tematizar o DHAA, é possível dizer que ambas as áreas ainda têm muito que avançar na pesquisa e na análise sobre a efetividade desse direito em termos concretos da vida, ou seja, implicar-se sobre os brasileiros que de fato têm fome.

\section{Referências}

ANJOS, João Guilherme Sampaio dos. O papel da assistência social na efetivação dos direitos sociais. Revista de Direito Sociais e Políticas Públicas, Brasília, v. 2, n. 1, p. 85-104, jan./jun. 2016. Disponível em: https://indexlaw.org/index.php/revistadspp/article/download/546/pdf. http://dx.doi.org/10.26668/IndexLawJournals/2525-9881/2016.v2i1.546.

ARRUDA, Ilma K. G. de; ARRUDA, Bertoldo K. G. de. Nutrição e desenvolvimento. Cad. Saúde Pública, Rio de Janeiro, v. 10, n. 3, p. 392-397, set. 1994. Disponível em: http://www. scielo.br/pdf/csp/v10n3/v10n3a19.pdf. https://doi.org/10.1590/S0102-311X1994000300019.

BARROS, Maria Sylvia Carvalho; TARTAGLIA, José Carlos. A política de alimentação e nutrição no Brasil: breve histórico, avaliação e perspectivas. Alim. Nutr., Araraquara, v.14, n.1, p. 109-121, 2003. Disponível em: http://serv-bib.fcfar.unesp.br/seer/index.php/ alimentos/article/viewFile/847/726\#: :text=BREVE\%20HIST\%C3\%93RICO\%2C\%20 AVALIA \%C3\% 87\%C3\% 83O\%20E\%20PERSPECTIVAS*,-Maria\%20Sylvia \%20 Carvalho\&text $=$ RESUMO 3 A \% 20A\%20revis\%C3\%A3o\%20hist\%C3\%B3rica\%20 das,solucionar\%20o\%20problema\%20nuitricional\%20brasileiro.

BAUER, Martin W; GASKELL, George. Pesquisa qualitativa com texto, imagem e som: um manual prático. Rio de Janeiro: Vozes, 2002.

BOSI, Maria Lúcia Magalhães. A face oculta da nutrição: ciência e ideologia. Rio de Janeiro: Espaço e Tempo; Ed. UFRJ, 1988. 
BURITY, Valéria et al. Direito humano à alimentação adequada no contexto da segurança alimentar e nutricional. Brasília-DF: ABRANDH, 2010. 204p.

BURLANDY, Luciene. A atuação da sociedade civil na construção do campo da Alimentação e Nutrição no Brasil: elementos para reflexão. Ciênc. saúde coletiva, Rio de Janeiro, v. 16, n. 1, p. 63-72, jan. 2011. Disponível em: http://www.scielo.br/pdf/csc/v16n1/v16n1a10.pdf. Acesso em: 13 ago. 2019. http://dx.doi.org/10.1590/S1413-81232011000100010.

CARTER, Kristie N; LANUMATA, Tolotea; KRUSE, Kerri; GORTON, Delvina. What are the determinants of food insecurity in New Zealand and does this differ for males and females? Aust NZ JPublic Health, v.34, n.6, p. 602-608, Dec. 2010. http://dx.doi.org/10.1111/j.1753-6405.2010.00615.x.

COORDENAÇÃO DE APERFEIÇOAMENTO DE PESSOAL DE NÍVEL SUPERIOR CAPES. Plataforma Sucupira. Disponível em: https://sucupira.capes.gov.br.

COPLE, Júlia. 'Passar fome no Brasil é uma grande mentira', diz Bolsonaro. O Globo, 19 jul. 2019. Disponível em: https://oglobo.globo.com/brasil/passar-fome-no-brasil-uma-grandementira-diz-bolsonaro-23818496. Acesso em 18 ago. 2019.

COSTA, Luiza Elena da; MESQUITA, Vânia Maria de; CAMPOS, Ana Paula. Moradores de rua, quem são eles? um estudo sobre a população de rua atendida pela Casa da Sopa "Capitão Vendramini” de Três Corações. Revista da Universidade Vale do Rio Verde, 13, n. 2, p. 285-297, 2015. Disponível em: http://periodicos.unincor.br/index.php/revistaunincor/ article/view/2281/pdf_377.http://dx.doi.org/10.5892/ruvrd.v13i1.2281.

COTTA, Rosângela Minardi Mitre; MACHADO, Juliana Costa. Programa Bolsa Família e segurança alimentar e nutricional no Brasil: revisão crítica da literatura. Rev. Panam Salud Publica, v. 33, n. 1, p. 54-60, 2013. Disponível em: https://www.scielosp.org/pdf/rpsp/2013.v33n1/54-60.

CULLERTON, Katherine; ADAMS, Jeans; FOROUHI, Nita; FRANCIS, Oliver; WHITE, Martin. What principles should guide interactions between population health researchers and the food industry? Systematic scoping review of peer-reviewed and grey literature. Obes Rev., v. 20, n. 8, p.1073-1084, Aug. 2019. http://dx.doi.org/10.1111/obr.12851.

CUTLER-TRIGGS, Cynthia; FRYER, George E; MIYOSHI, Thomas J; WEITZMAN, M. Increased rates and severity of child and adult food insecurity in households with adult smokers. Arch Pediatr Adolesc Med., v. 162, n. 11, p. 1056-1062, Nov. 2008. http://dx.doi. org/10.1001/archpediatrics.2008.2.

ENGELMANN, João Gilberto. Direitos fundamentais e efetividade: o desafio da inclusão social numa economia não sustentável. Revista Direito em Debate, v. 23, n. 42, p. 68-82, 2014. Disponível em: https://www.revistas.unijui.edu.br/index.php/revistadireitoemdebate/article/ view/3113/3507. https://doi.org/10.21527/2176-6622.2014.42.68-82.

GUERRA, Lúcia Dias da Silva. Alimentação: um direito humano em disputa - focos temáticos para compreensão e atuação em segurança alimentar e nutricional. Ciênc. saúde coletiva, v. 24, n. 9, p. 3369-3394, set. 2019. Disponível em: https://www.scielo.br/pdf/csc/v24n9/1413-8123csc-24-09-3369.pdf. https://doi.org/10.1590/1413-81232018249.20302017. 
GUERRA, Lúcia Dias da Silva. Direito humano à alimentação adequada e atuação profissional em saúde pública. Tese (Doutorado) - Programa de Pós-Graduação de Nutrição em Saúde Pública da Faculdade de Saúde Pública da Universidade de São Paulo, 2017. Disponível em: https://teses.usp.br/teses/disponiveis/6/6138/tde-29112017-001605/publico/ LuciaDiasdaSilvaGuerraRevisada.pdf.

HATAB, Assem Abu; CAVINATO, Maria Eduarda Rigo; LINDEMER, August; LAGERKVIST, Carl-Johan. Urban sprawl, food security and agricultural systems in developing countries: a systematic review of the literature. Cities, v. 24, p. 129-142, Nov. 2019. Disponível em: https:// www.sciencedirect.com/science/article/pii/S0264275118310485/pdfft?md5=60574f9be6fd6c 0e8674704de0f8f45f\&pid=1-s2.0-S0264275118310485-main.pdf. https://doi.org/10.1016/j. cities.2019.06.001.

HIGGINS, Julian; GREEN, Sally. Cochrane handbook for systematic reviews of interventions. Version 5.1.0. Mar 2011. Editors: Julian PT Higgins, Sally Green. Oxford, UK: Cochrane Collaboration, 2011. Disponível em: https://handbook-5-1.cochrane.org/.

INSTITUTO BRASILEIRO DE GEOGRAFIA E ESTATÍSTICA - IBGE. Síntese de indicadores sociais: uma análise das condições de vida da população brasileira: 2018. Coordenação de População e Indicadores Sociais. Rio de Janeiro: IBGE, 2018. 151 p. (Estudos e pesquisas. Informação demográfica e socioeconômica; n. 39). Disponível em: https://biblioteca.ibge. gov.br/visualizacao/livros/liv101629.pdf.

KAISER, Lucia L.; MELGAR-QUIÑONEZ, Hugo R.; TOWNSEND, Marilyn S.; NICHOLSON, Yvonne; FUJI, Mary Lavender; MARTIN, Anna C.; LAMP, Cathi L. Food insecurity and food supplies in Latino households with young children. J Nutr Educ Behav., v. 35, n. 3, p. 148-153, May/June 2003. https://doi.org/10.1016/S1499-4046(06)60199-1.

KERSEY, Margaret; GEPPERT, Joni; CUTTS, Diana B. Hunger in young children of Mexican immigrant families. Public Health Nutr, v. 10, n. 4, p. 390-395, 2007. Disponível em: https:// www.cambridge.org/core/services/aop-cambridge-core/content/view/4F3B036BEBAA389 935D8F4A34270381A/S1368980007334071a.pdf/hunger-in-young-children-of-mexicanimmigrant-families.pdf. https://doi.org/10.1017/S1368980007334071.

KOKABISAGHI, Fatemeh. Assessment of the effects of economic sanctions on Iranian's right to health by using human rights impact assessment tool: a systematic review. Int J Health Policy Manag, v. 7, n. 5, p. 374-393, May 2018. https://doi.org/10.15171/ijhpm.2017.147.

LISBOA, Renata Cardoso. Direito humano à alimentação adequada. Revista Eletrônica de Direito, out. 2013. Disponível em: http://npa.newtonpaiva.br/direito/?p=1464. Acesso em: 24 ago. 2018.

MACHADO, Renato Luiz Abreu. Direito humano à alimentação adequada. Publicado em: 29 maio 2017. Disponível em: http://www4.planalto.gov.br/consea/acesso-a-informacao/ institucional/conceitos/direito-humano-a-alimentacao-adequada. Acesso em: 22 ago. 2018.

MAIA, M.S.F.; BARACHO, H.U.A. A efetividade dos direitos sociais no Brasil: comentários sobre o papel do Judiciário. 2007. p. 53-68. Disponível em: http://periodicos.ufpb.br/index. php/primafacie/article/viewFile/6535/4098. Acesso em: 01 abr. 2019. 
MALUF, Renato S. Segurança alimentar e nutricional. 2. ed. Rio de Janeiro: Vozes, 2009.

MARTINS, Ana Paula Bortoletto et al. Transferência de renda no Brasil e desfechos nutricionais: revisão sistemática. Rev. Saúde Pública, São Paulo, v. 47, n. 6, p. 1159-1171, dez. 2013. Disponível em: https://www.scielo.br/pdf/rsp/v47n6/0034-8910-rsp-47-06-01159.pdf. https://doi.org/10.1590/S0034-8910.2013047004557.

MINISTÉRIO DO DESENVOLVIMENTO SOCIAL E COMBATE À FOME. Câmara Interministerial de Segurança Alimentar e Nutricional - CAISAN. Plano Nacional de Segurança Alimentar e Nutricional: 2012/2015. Brasília-DF: CAISAN, 2011. Disponível em: https://www.mds.gov.br/webarquivos/publicacao/seguranca_alimentar/Plano_ Caisan.pdf.

NAÇÕES UNIDAS. Declaração Universal dos Direitos Humanos. Adotada e proclamada pela Assembleia Geral das Nações Unidas (resolução 217 A III) em 10 de dezembro 1948. UNICEF. Disponível em: https://www.unicef.org/brazil/declaracao-universal-dos-direitoshumanos. Acesso em: 21 abr. 2021.

NASCIMENTO, Adriano Roberto Afonso do; MENANDRO, Paulo Rogério Meira. Análise lexical e análise de conteúdo: uma proposta de utilização conjugada. Estudos e Pesquisas em Psicologia, UERJ, Rio de Janeiro, v. 6, n. 2, p. 72-88, dez. 2006. Disponível em: http://pepsic. bvsalud.org/pdf/epp/v6n2/v6n2a07.pdf.

NUNES, Mercés da Silva. O direito fundamental à alimentação e o princípio da segurança. Rio de Janeiro: Elsevier, 2008.

OLIVEIRA SOBRINHO, Afonso Soares. A dignidade humana como afirmação histórica. Revista Espaço Acadêmico, v. 13, n. 144, p. 54-62, maio 2013. Disponível em: https://periodicos. uem.br/ojs/index.php/EspacoAcademico/article/view/19627/11102.

OSÓRIO, Mônica Maria; RIBEIRO, Marisilda de Almeida; COSTA, Emilia Chagas; SILVA, Silvia Patrícia de Oliveira; FERNANDES, Carolina Estevam. Disponibilidade familiar de alimentos na Zona da Mata e Semi-Árido do Nordeste do Brasil. Rev. Nutr., Campinas. v. 22, n. 3, p. 319-329, jun. 2009. Disponível em: https://www.scielo.br/pdf/rn/v22n3/v22n3a02.pdf. https://doi.org/10.1590/S1415-52732009000300002.

ROCHA, Cecília; BURLANDY, Luciene; MAGALHÃES, Rosana. Segurança alimentar e nutricional: perspectivas, aprendizados e desafios para as políticas públicas. Rio de Janeiro: Fiocruz, 2013.

ROSAS, Lisa G; HARLEY, Kim; FERNALD, Lia CH; GUENDELMAN, Sylvia; MEJIA, Fabiola; NEUFELD, Lynnette M.; ESKENAZI, Brenda. Dietary associations of household food insecurity among children of Mexican descent: results of a binational study. J Am Diet Assoc., v. 109, n. 12, p. 2001-2009, Dec. 2009. https://doi.org/10.1016/j. jada.2009.09.004.

SALES, Bruno Olivo de. A efetividade do direito à saúde no sistema constitucional brasileiro. 2005. 75f. (Graduação em Direito) - Universidade Federal do Paraná, Curitiba, 2005. 
SANTOS, Marcos André Couto. A efetividade das normas constitucionais (as normas programáticas e a crise constitucional). Revista de Informação Legislativa. Brasília-DF, ano 37, n. 147, p. 5-14, jul./set. 2000. Disponível em: https://www2.senado.leg.br/bdsf/bitstream/ handle/id/602/r147-01.PDF? sequence $=4 \&$ is Allowed $=\mathrm{y}$.

SHOAE, Nahid Zerafati; OMIDVAR, Nasrin; GHAZI-TABATABAIE, Mahmood; RAD, Anahita Houshiar; FALLAH, Hajieh; MEHRABI, Yadollah. Is the adapted Radimer/Cornell questionnaire valid to measure food insecurity of urban households in Tehran, Iran? Public Health Nutr, v. 10, n. 8, p. 855-861, Aug. 2007. https://doi.org/10.1017/S1368980007441465.

SOARES, Fábio Veras; PEREZ RIBAS, Rafael; OSÓRIO, Rafael Guerreiro. Evaluating the impact of Brazil's Bolsa Família: cash transfer programs in comparative perspective. Latin American Research Review, v. 45, n. 2, p. 173-190, 2010. https://doi.org/10.1353/lar.2010.0017.

SOARES, Sônia. Análise do direito humano à alimentação adequada: um direito social e político. Revista de Direito Sanitário, São Paulo, v. 19 n. 2, p. 36-54, jul./out. 2018. Disponível em: https://www.revistas.usp.br/rdisan/article/view/152569/149064. Acesso em 13 ago. 2019. https://dx.doi.org/10.11606/issn.2316-9044.v19i2p36-54.

VALENTE, Flávio Luiz Schieck. Direito humano à alimentação: desafios e conquistas. São Paulo: Editora Cortez, 2002.

ZIMMERMANN, Clóvis Roberto. Os programas sociais sob a ótica dos direitos humanos: o caso do Bolsa Família do governo Lula no Brasil. Sur, Rev. int. direitos human., São Paulo, v. 3, n. 4, p. 144-159, jun. 2006. Disponível em: https://www.scielo.br/pdf/sur/v3n4/08.pdf.

Bruna Nascimento da Silva - Especialização em Direito Regulatório Sanitário pela Faculdade Oswaldo Cruz; graduação em Direito pela Faculdade Pan-Amazônica (FAPAN); graduação em Nutrição pela Universidade Federal do Pará (UFPA). Advogada. São Paulo/SP, Brasil. E-mail: b.nasc.s@gmail.com

Lúcia Dias da Silva Guerra - Doutorado em Ciências (Nutrição em Saúde Pública) pela Faculdade de Saúde Pública da Universidade de São Paulo (FSP-USP); mestrado em Saúde Coletiva pelo Instituto de Saúde Coletiva da Universidade Federal de Mato Grosso (ISC/UFMT). Professora do Curso de Graduação em Nutrição na Universidade Anhanguera, campus Santana. Nutricionista. São Paulo/SP. Brasil. E-mail: luciadsguerra@usp.br

Leonardo Carnut - Pós-Doutorado em Saúde Pública (Ciências Sociais e Humanas em Saúde) pela Faculdade de Saúde Pública da Universidade de São Paulo (FSP-USP); especialização em Direito Sanitário pelo Instituto de Direito Sanitário Aplicado (IDISA); graduação em Ciências Sociais pela Universidade Federal de Pernambuco (UFPE). Professor Adjunto da Universidade Federal de São Paulo (Unifesp). São Paulo/SP. Brasil. E-mail: leonardo.carnut@unifesp.br 